\title{
Study of the Evolutionary Relationships among Limonium Species (Plumbaginaceae) Using Nuclear and Cytoplasmic Molecular Markers
}

\author{
Carmen Palacios, $, \nmid, 1$ J osep A. Rosselló,*,ł and Fernando González-Candelas*, † \\ * Institut Cavanilles de Biodiversitat i Biologia Evolutiva, † Departament de Genètica, and ¥ Departament de Biologia Vegetal, \\ Universitat de València, Valencia E-46071, Spain \\ Received February 2, 1999; revised M ay 24, 1999
}

The genus Limonium, due to the patchiness of the natural habitats of its species as well as the high frequency of hybridization and polyploidy and the possibility of reproduction by apomixis, provides an example of all the principal mechanisms of rapid speciation of plants. As an initial study of evolution in this genus, we have analyzed intra- and interspecific variability in 17 species from section Limonium, the largest in the genus, based on RFLPs of cPDNA and nuclear rDNA ITS sequences. In the cpDNA analysis, 21 restriction enzymes were used, resulting in 779 fragments, 490 of which were variable and 339 parsimony informative. $L$. furfuraceum exhibited two relatively divergent cpDNA haplotypes. The relationships found among the species based on cpDNA restriction fragments were coincident using different methods of phylogenetic analysis. Due to the presumed reticulate evolution in the genus Limonium, the comparison of these results with data from the nuclear DNA was necessary; ITS sequences were analyzed. The final alignment contained 488 characters, of which 198 were variable and 156 parsimony informative. Two relatively divergent ITS types were present at the intraindividual level in L. delicatulum, a triploid species. Each type was related to ITS from different groups of diploid Limonium species, one with a base haploid chromosome number $\mathbf{n}=\mathbf{8}$ (represented by L. cossonianum) and the other with $n=9$ (represented by $L$. minutum). The different phylogenetic inference methods used for the analysis of ITS sequences rendered very similar topologies. In general, the relationships among the species studied were coincident with those obtained with the chloroplast genome. Both nuclear and cytoplasmic markers support the polyphyly of section Li monium, with at least two species, L. narbonense and $L$. vulgare, clearly divergent from the rest. Moreover, the remaining subsections into which section Limonium is currently divided seem to be artificial. 2000 Academic Press

\footnotetext{
${ }^{1}$ Present address: INTA, Centro de Astrobiología, Ctra. de Ajalvir km. 4, 28850 Torrejón deArdoz, Madrid, Spain.
}

\section{INTRODUCTION}

Taxonomic complexity has frequently been related to the mating system of plants. Hence, taxa having breeding systems favoring selfing or asexual reproduction (apomixis and clonality) are usually prone to taxonomical controversy (Richards, 1986). Apomictic plants circumventing sexuality, obligately or facultatively, defy classical species concepts and make the delimitation of taxa a difficult task (Richards et al ., 1996).

Limonium is the most species rich and widespread genus of Plumbaginaceae, although the number of species reported in the genus is rather speculative. A very high percentage of Limoni um diversity is centered in the Mediterranean basin with nearly 300 taxa currently used in regional floras and checklists (Erben, 1993; Greuter et al., 1989). A significant portion of these taxa bel ong to section Limonium, one of the 12 sections in which the genus has been traditionally split (Boissier, 1848). In turn, section Limonium has been divided into six subsections (Boissier, 1848; see al so Table 1).

Several of these sections were later grouped into subgeneric ranks. Thus, Pax (1897) included sections Polyarthrion, Myriolepis, Siphonantha, and PsilIyostachys within subgenus Si phonantha. On the other hand, Pignatti (1971) raised section Pteroclados to the subgeneric level and excluded section Myriolepis from subgenus Siphonantha to create a new subgenus (subgenus Myriolepis). Other analytical treatments have dealt with some of the sections recognized by Boissier and Pax (section Circinaria, section Schyzimenium, section Psillyostachis, section Schyzopethalum, section Pterol imon) as separate genera (Linczveski, 1968).

Both sexual (diploid and tetraploid) and apomictic (spanning triploid to hexaploid cytotypes) species have been reported in section Limonium. Nevertheless, diploid species are few, and polyploid agamic species constitute the largest portion of the diversity currently known in this section. Several competing hypotheses, based mainly on karyological data, regarding the origin of polyploid Limonium species have been postulated (Dolcher and Pignatti, 1971; Erben, 1978, 1979). Dol- 
cher and Pignatti (1971) suggested that triploid taxa arose through hybridization between diploid and tetraploid species, the latter having originated from diploid ancestors. In contrast, Erben $(1978,1979)$ noted that within section Limonium, diploid species show two basic chromosome numbers $(n=8$ and $n=9)$ and postulated that the complement of the polyploids arose through several combinations, involving reduced and unreduced gametes, of the $n=8$ and $n=9$ genomes. Hence, triploid $(2 n=24,25,26$, and 27$)$ and tetraploid $(2 n=34,35$, and 36$)$ taxa combine genomes of the two basic cytotypes. Although conflicting, both hypotheses agree that interspecific hybridization has played a substantial role in the evolution of section Limonium. However, this has not been tested by means of a rigorous phylogenetic analysis. Unfortunately, the very similar morphology exhibited by most members of section Limonium (with most characters showing continuous variation) has prevented the use of morphol ogical characters in a phylogenetic (cladistic) context. Theoretically, molecular analyses could circumvent this drawback and offer robust hypotheses on the evolution of these species.

Molecular approaches have been applied to some genera with a large apomictic el ement in order to detect species (microspecies) boundaries and to trace the origins of apomictics (Campbell et al., 1997). Molecular data have been rarely applied in Plumbaginaceae (Chase et al., 1993; Williams et al., 1994; Fuertes et al., 1999). Recently, Lledó et al. (1998) used rbcL sequence data from species of Limonium, Limoniastrum, Acanthol inum, Dictyol imon, Psilli ostachys, Armeria, Ceratostigma, and Plumbago to evaluate the monophyly and phylogenetic relationships of Plumbaginaceae. Because the goals of that study were to elucidate relationships at higher taxonomic levels within this family, few conclusions regarding Limonium other than its monophyly were attained.

Sequences of the nuclear rDNA internal transcribed spacers (ITS region) have been widely applied to depict evolutionary relationships at lower taxonomic levels, notably at the intrageneric ones (Baldwin et al., 1995). In addition, the ITS region has been a valuable tool for tracing the hybrid origin of diploid (Sang et al., 1995) and polyploid (van Houten et al., 1993; Kim and J ansen, 1994; Wendel et al., 1995; Roel ofs et al., 1997) species in flowering plants. Presumed uniparental (maternal) inheritance of the chloroplast genome in Limonium (Harris and Ingram, 1991) and the absence of intramolecular recombination prevent the appearance of reticulation in cpDNA phylogenies, as opposed to those based on morphology or nuclear DNA. Therefore, when nuclear phylogenies conflict with molecular markers obtained from the chloroplast genome, hybridization or introgression can be suspected (Doyle, 1992; Rieseberg and Brunsfeld, 1992; Sol tis et al., 1992).

In this work, nuclear (ITS sequences) and organellar
(RFLP of cpDNA) markers have been obtained from 21 Limonium species, mostly from section Limonium, inhabiting the western Mediterranean basin. Most of them are endemic to this area, and some are also endangered due to the fragility of the ecosystems that these species inhabit. Species representing the main karyological and reproductive systems present in this section have been included in this work. The main goals of this study were to check the monophyly of section Limonium, to test the current division of this section into subsections, and to assess its relationships with other sections of the genus Limonium. Also, we have explored whether molecular markers can shed some light on the origins of polyploidy in apomictic species from this section.

\section{MATERIALS AND METHODS}

\section{Plant Samples and DNA I solation}

Twenty-six Limonium populations corresponding to 17 species from section Limonium and 4 species from other sections of the genus were analyzed for cpDNA variation and/or ITS sequence variation (Table 1). This table also shows the number of individuals sampled per population, voucher specimen numbers, locality of origin of the populations, and chromosome numbers and mode of reproduction of each species. The choice of species was dictated mainly by the availability of material. At least 1 species from each of the currently recognized subsections of the section Limonium was included, with the only exception being subsection Sarcophyllae, for which no material was available. All basic chromosome numbers were included in the sampling by considering diploid ( $n=6,8$, and 9), triploid $(2 \mathrm{n}=25,26$, and 27$)$, and tetraploid $(2 \mathrm{n}=36)$ species, with sexual and apomictic taxa among them.

Plant materials were collected as 1-3 g of fresh leaf tissue from the greenhouse or from the field and stored at $-80^{\circ} \mathrm{C}$ until processed. Fresh leaves were not available for L. Iobatum, and therefore dried leaves from herbarium specimens were used for DNA extraction. When available, leaves from two or more individuals from each population were pooled (Table 1). This approach has been suggested as a strategy to detect intraspecific or intraindividual variation both in cpDNA RFLPs and ITS sequence analyses (Soltis et al., 1989; Baldwin et al., 1995). Total DNA was isolated using the CTAB method (Doyle and Doyle, 1991). One further chlor oform-isoamylal cohol (24:1) extraction was done if samples were still turbid after the first organic extraction.

\section{RFLP Analysis of the Chloroplast Genome}

Variation among cpDNAs of Limonium was detected by DNA digestion with 21 restriction endonuclease enzymes according to suppliers' instructions. We employed 3 four-cutter enzymes (Cfol , Haell , and Mspl) 
TABLE 1

Limonium Species Used for the Study of cPDNA RF LP Variation and ITS Sequencing

\begin{tabular}{|c|c|c|c|c|c|c|}
\hline Species & Populations & Voucher & $\begin{array}{c}\text { EMBL } \\
\text { Accession } \\
\text { no. }\end{array}$ & Individuals & $\begin{array}{l}\text { Chromosome } \\
\text { no. (2n) }\end{array}$ & $\begin{array}{l}\text { Reproduction } \\
\text { mode }\end{array}$ \\
\hline \multicolumn{7}{|l|}{ Sect. Limonium } \\
\hline \multirow{2}{*}{\multicolumn{7}{|c|}{$\begin{array}{l}\text { Subsections } \\
\text { Limonium }\end{array}$}} \\
\hline & & & & & & \\
\hline L. narbonense Mill. & Almardà (Valencia)* & J AR-96132 & AJ 222838 & 2 & 36 & Sexual \\
\hline L. vulgare Mill. & Cantabria & J AR-96085 & Aj 222839 & 1 & 36 & Sexual \\
\hline \multicolumn{7}{|l|}{ Densiflorae Boiss. } \\
\hline $\begin{array}{l}\text { L. dufourii (Girard.) } \\
\text { Kuntze }\end{array}$ & Cullera (Valencia) & J AR-96051 & AJ 222840 & 4 & 27 & Apomixis \\
\hline $\begin{array}{l}\text { L. camposanum } \\
\text { Erben }\end{array}$ & Cala Pi (Mallorca)* & J AR-95111 & AJ 222841 & 1 & 27 & Apomixis \\
\hline $\begin{array}{l}\text { L. gymnesicum } \\
\text { Erben }\end{array}$ & Sant Pere (Mallorca)* & J AR-94328 & AJ 222842 & 1 & 27 & Apomixis \\
\hline \multirow[t]{2}{*}{$\begin{array}{l}\text { L. interjectum Soler } \\
\quad \& \text { Rosselló }\end{array}$} & $\begin{array}{l}\text { Cala Blanca (J avea, Ali- } \\
\text { cante) }\end{array}$ & J AR-96127 & AJ 222843 & 1 & Unknown & Apomixis \\
\hline & EI LIano (J avea, Alicante) ${ }^{\wedge}$ & J AR-96124 & AJ 222844 & 1 & & \\
\hline $\begin{array}{l}\text { L. girardianum } \\
\text { (Guss.) Fourr. }\end{array}$ & EI Saler (Valencia)^ & J AR-96027 & Aj 222845 & 1 & 26 & Apomixis \\
\hline \multicolumn{7}{|l|}{ Dissitiflorae Boiss } \\
\hline $\begin{array}{l}\text { L. delicatulum } \\
\text { (Girard) Kuntze }\end{array}$ & $\begin{array}{l}\text { Cala Blanca ( } \text { avea, Ali- } \\
\text { cante)* }\end{array}$ & J AR-96018 & AJ $222846-51$ & 8 & 25 & Apomixis \\
\hline L. cavanillesii Erben & Torre Badún (Castellón) & J AR-96217 & AJ 222852 & 6 & 27 & Apomixis \\
\hline $\begin{array}{l}\text { L. anguste } \\
\text { bracteatum Erben }\end{array}$ & Pobla Farnals (Valencia)* & J AR-96127 & AJ 222853 & 1 & 26 & Apomixis \\
\hline \multirow[t]{2}{*}{$\begin{array}{l}\text { L. rigualii MB } \\
\text { Crespo \& Erben }\end{array}$} & $\begin{array}{l}\text { Cala Blanca ( } \text { avea, Ali- } \\
\text { cante) }\end{array}$ & J AR-96126 & AJ 222854 & 2 & 27 & Apomixis \\
\hline & EI Llano (J avea, Alicante) & J AR-96125 & & 5 & & \\
\hline $\begin{array}{l}\text { L. cossonianum } \\
\text { Kuntze }\end{array}$ & Formentera (Baleares) & J AR-97005 & AJ 132331 & 1 & 16 & Sexual \\
\hline \multicolumn{7}{|l|}{ Steirocladae Boiss. } \\
\hline \multirow[t]{3}{*}{$\begin{array}{l}\text { L. virgatum (Willd.) } \\
\text { Fourr. }\end{array}$} & Cabo Salines (Mallorca)* & J AR-95025 & AJ 222855 & 1 & 27 & Apomixis \\
\hline & $\begin{array}{l}\text { Cala Blanca (J avea, Ali- } \\
\text { cante) }\end{array}$ & J AR-96141 & & 1 & & \\
\hline & EI Saler (Valencia) $)^{\wedge}$ & J AR-96028 & & 1 & & \\
\hline \multirow{2}{*}{$\begin{array}{l}\text { L. furfuraceum } \\
\text { (Lag.) Kuntze }\end{array}$} & Cabo Huertas (Alicante) & J AR-96219 & AJ 222856 & 10 & 18 & Sexual \\
\hline & Sta. Pola (Alicante) & J AR-96218 & & 10 & & \\
\hline L. tenuicauleErben & Artà (Mallorca)* & AR-95112 & AJ 222857 & 1 & 18 & Sexual \\
\hline $\begin{array}{l}\text { L. minutum (L.) } \\
\text { Chaz. }\end{array}$ & Formentera (Baleares) & J AR-97006 & AJ 132332 & 1 & 18 & Sexual \\
\hline \multicolumn{7}{|l|}{ Hyalol epidae Boiss. } \\
\hline $\begin{array}{l}\text { L. dichotomum } \\
\text { (Cav.) Kuntze }\end{array}$ & Aranjuez (Madrid) & J AR-96501 & AJ 222858 & 1 & 18 & Sexual \\
\hline \multicolumn{7}{|l|}{ Sect. Polyarthrion Boiss. } \\
\hline $\begin{array}{l}\text { L. caesium (Girard) } \\
\text { Kuntze }\end{array}$ & Villena (Valencia)* & J AR-94029 & AJ 222859 & 1 & 18 & Sexual \\
\hline \multicolumn{7}{|l|}{ Sect. Pterodlados } \\
\hline $\begin{array}{l}\text { L. Iobatum (L be.) } \\
\text { Chaz. }\end{array}$ & Terreros (Almería) & VAB-96/4628 & AJ 132333 & 1 & 12 & Sexual \\
\hline $\begin{array}{c}\text { L. sinuatum (L) Mill. } \\
\text { Sect. Schizhymenium } \\
\text { Boiss. }\end{array}$ & C. Gata (Almería)^ & J AR-96850 & AJ 222860 & 1 & 16 & Sexual \\
\hline L. echioides (L) Mill. & $\begin{array}{l}\text { Cala Blanca (J avea, Ali- } \\
\text { cante) } \wedge\end{array}$ & J AR-96129 & AJ 222861 & 1 & 18 & Sexual \\
\hline
\end{tabular}

* Samples from University of Valencia greenhouse facility.

$\wedge$ Samples used on ITS sequencing study exclusively. The rest have been used on both studies except for the Sta. Pola population sample of L. furfuraceum, which was used only in the cpDNA analysis (see text for further details). 


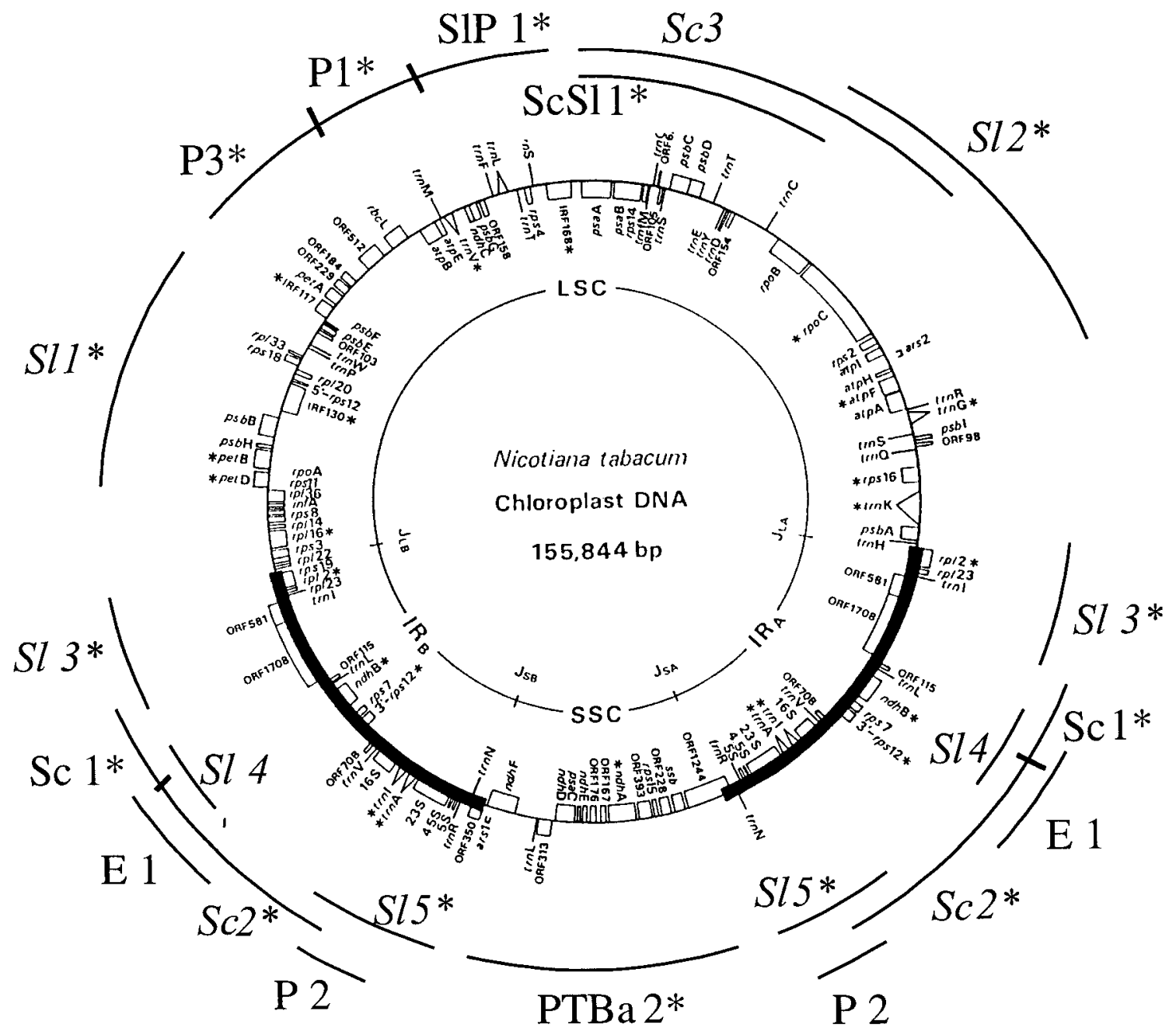

FIG. 1. cpDNA clones from Limonium narbonense superimposed on the chloroplast genetic map of tobacco. A genomic library from L. narbonense was obtained from an enriched cpDNA extraction (Ko et al., 1984) followed by digestion and cloning of restriction fragments following standard protocols (Maniatis et al., 1982). cpDNA fragments of L. narbonense were detected and mapped using cpDNA clones from Nicotiana tabacum, kindly provided by M. Sugiura (Sugiura et al., 1986), as probes. L. narbonensecpDNA cl ones are denoted by the restriction enzyme with which they were obtained (SI, Sall; Sc, Sacl ; E, E coRV; P, Pstl), followed by an arbitrary number. Clones shown in italics are in EMBL 20 phage vector; the rest are clones or subclones in pUCBM20 plasmid vector. An asterisk indicates clones used in the study of section Limonium.

and 18 six-cutters (Asp700, Aval, BamHI, Bcll, Bfrl, BgllI, Clal, Dral, EcoRI, EcoRV, HindlII, Ncol, Pstl, Sacl, Sall, Scal, Xbal, and Xhol). Restriction fragments were separated by electrophoresis on $0.7-1 \%$ agarose gels at approximately $2.5 \mathrm{~V} / \mathrm{cm}$ for $12 \mathrm{~h}$ with TBE $0.5 \times$ buffer. Nonradioactive hybridization methods were used to detect cpDNA fragments. Transfer of DNA to nylon filters (Hybond-N, Amersham) by Southern blotting, filter prehybridization, hybridization, and detection were performed following manufacturer's instructions (Boehringer Mannheim, B.M.) with slight modifications. Probes werelabel ed with digoxigenin-11dUTP using the random priming method. Hybridizations were performed at $65^{\circ} \mathrm{C}$ overnight, and the filters were washed at $60^{\circ} \mathrm{C}$ twice for $15 \mathrm{~min}$ in a prewarmed $0.1 \%$ SDS, $0.5 \times$ SSC solution. Probe removal prior to reutilization was performed by washing the membranes in distilled water for $1 \mathrm{~min}$, followed by incubating twice for $15 \mathrm{~min}$ at $60^{\circ} \mathrm{C}$ in $0.4 \mathrm{~N} \mathrm{NaOH}, 0.1 \%$ SDS prewarmed solution, and finally rinsing them thoroughly in $2 \times$ SSC. Detection of hybridized probes in the first hybridizations was performed by immunochemioluminescence with CSPD substrate (B.M.) followed by autoradiography. Better results were obtained by employing colorimetric reagents (BCIP and NBT; B.M.) to detect the labels in a subsequent rehybridization.

A total of $10 \mathrm{cpDNA}$ restriction fragments obtained from a genomic library constructed from $L$. narbonense (Fig. 1) and a clone from the cpDNA of Nicotiana tabacum were used as probes to detect homologous fragments among the different species. Clones were labeled separately and combined in four batches for 
filter hybridization, comprising $127 \mathrm{~kb}$ in total, which should represent a large fraction of the chloroplast genome (Palmer, 1991).

Fragment observation and reconstruction of the presence-absence character state data matrix were made directly on the autoradiograms from the different hybridizations (Fragment Occurrence Analysis, FOA; Bremer, 1991a). Care was taken not to score a band more than once by overlapping autoradiograms probed with adjacent probe/enzyme combinations. Any band shared in these autoradiograms was scored only once.

Data analysis. Weighted parsimony (Sankoff, 1975) or "generalized parsimony" was used to analyze the presence-absence character state data using the stepmatrix option from PAUP 3.1 (Swofford, 1993). We followed the recommendations in Albert et al. (1992) but with the following modification. These authors proposed a character state weighting of gains over losses by a factor of 1.3 for analyses at low taxonomic levels, such as species within a genus. This implies a probability of losing a site of 0.565 over 0.435 of gaining it. Because we have screened fragments instead of restriction sites, with the resulting 3:1 ratio character difference among these two types of markers (Bremer and J ansen, 1991b), a fragment gain could result from a gain of a site with probability of $2 / 3$ but also from losing a site with probability of $1 / 3$, with these probabilities being the opposite for losing a fragment. Combining these two considerations, the final cost of fragment gains over losses would be 21:19 (i.e., $1 /[(0.565+2 \cdot 0.435) / 3]: 1 /[(0.435+2 \cdot 0.565) / 3]$. Moreover, Al bert et al . (1992) suggested trying other weighting factors in the range 1.0 to 2.5 for a comparative check. Consequently, we also tried the corresponding weights of these extreme values obtained by applying the previous argument as alternative step-matrices for the FOA approach. In these matrices, gains were weighted as equal to losses for the first extreme value, which is equivalent to Wagner parsimony, and the step-matrix 23:17 was used for the 2.5 factor. A heuristic search ignoring invariant characters and using ACCTRAN optimization was employed for the stepmatrix analyses. To avoid problems associated with tree islands (Maddison, 1991), the strategy suggested by Doyle and Doyle (1993) was followed. It consists of conducting searches using 100 random addition sequence option, followed by TBR branch swapping, retaining only a single tree from each run and only the most parsimonious trees (MPT) from all runs. Asymmetric weighting required the definition of ancestral character states, and we chose the option all missing-data for it and forced ingroup to monophyly ["enhanced Wagner" approach (Albert et al., 1992)].

Bootstrap analysis (Felsenstein, 1985) was used to assess the reliability of the phylogenetic reconstructions. One-hundred bootstrap replicates were performed for thethree parsimony approaches with heuris- tic search options as above, except for weighted parsimony in which the stepwise addition was closest instead of random. In this last case, near-MPTs up to 10 steps longer were al so examined as al ternative phylogenetic hypotheses. Phylogenetic information content of the entire data set was also estimated by the skewness coefficient $\left(g_{1}\right.$; Hillis, 1991) using the random trees option (set to 1000 trees) of PAUP (Swofford, 1993).

Pairwise distances among populations were calculated from the character state data matrix using the nucleotide divergence estimate for restriction fragment data with the iterative method of Nei (1987). Divergence estimates from the 3 four-cutters and the 18 six-cutters were averaged according to $\mathrm{Nei}$ and Miller (1990). An unrooted neighbor-joining (NJ ) dendrogram (Saitou and Nei, 1987) was obtained from this matrix using the program NEIGHBOR from the PHYLIP package (Felsenstein, 1993).

\section{Sequence Analysis of theITS Region}

Amplification and sequencing strategies. The ITS region comprises ITS-1, ITS-2, and the 5.8S subunit of the nuclear rDNA cistron (Baldwin et al., 1995) and was amplified by PCR using universal eukaryote primers designed by White et al. (1990). PCRs were performed in a $25-\mu \mathrm{L}$ total volume containing $1.5 \mathrm{mM} \mathrm{M} \mathrm{gCl}_{2}, 0.2$ $\mathrm{mM}$ each dNTP, $0.2 \mu \mathrm{M}$ each primer, approximately 3 ng of template DNA, $2.5 \mu \mathrm{L}$ of 10× Taq buffer, and 1 unit of Taq DNA polymerase. The profile for amplification reactions consisted of an initial step at $94^{\circ} \mathrm{C}$ for 2 min, followed by $30 \mathrm{cycles}$ at $94^{\circ} \mathrm{C}$ for $1 \mathrm{~min}, 55^{\circ} \mathrm{C}$ for 30 $\mathrm{s}$, and $72^{\circ} \mathrm{C}$ for $45 \mathrm{~s}$; the last cycle was followed by a 9-min extension phase at $72^{\circ} \mathrm{C}$; then, samples were held at $4-6^{\circ} \mathrm{C}$.

Manual sequencing was performed for all species analyzed in the previous section at least once. PCR products were purified from primers and dNTPs using Ultrafree (Millipore) filters. Cycle-sequencing reactions of these purified products (200 ng, approx) were conducted using the AmpliCycle Sequencing kit (PerkinElmer), following the manufacturer's instructions for the $\left[\gamma^{33} \mathrm{P}\right]$ ATP end-labeling reaction procedure.

Automated sequencing was performed at least twice for each population using theABI PRISM DyeTerminator Cycle Sequencing Ready Reaction kit (Applied Biosystems, Inc.) following manufacturer's instructions with some modifications. Purification of PCR products (100 ng, approx) from dNTPs and primers was performed by incubation at $37^{\circ} \mathrm{C}$ for $15 \mathrm{~min}$ with exonuclease and shrimp alkaline phosphatase, followed by $15 \mathrm{~min}$ at $80^{\circ} \mathrm{C}$. Centri-Sep (Princeton Separations, Inc.) spin columns were used to purify extension products from excess dye terminators after cycle sequencing reactions. Electrophoresis was performed on $4 \%$ polyacrylamide at constant vol tage $(2500 \mathrm{~V})$ on $\mathrm{ABI}$ 377 or 373 automated DNA sequencers. No differences 
were observed between automated and manually obtained sequences in those species analyzed with both techniques.

Some species showed sequence uncertainties in certain nucleotide positions, which could be due either to insufficient sequence resolution in those positions or to real polymorphisms. They were scored as ambiguities following the IUB code. In one case (L. delicatulum), the amount of polymorphism prevented any meaningful interpretation of the nucleotide sequence, and it was necessary to sequence cl oned PCR products from single individuals. In this case, ITS PCR products were cloned using the pGEM-T E asy vector system (Promega Corp.), and at least two clones from each individual were sequenced (Bloch, 1991). Recombinant plasmid DNAs were isolated following the modified mini alkaline-lysis/ PEG precipitation procedure recommended by $A B I$ (User bulletin No. 18). Cloned fragments were sequenced automatically using T7 and SP6 universal primers.

Sequence alignment. Direct and reverse sequences belonging to the same population or clone were assembled using the program Sequencher (Gene Codes Corp., v. 3.0), and a consensus sequence was obtained. The resulting consensus sequences were aligned using the program PILEUP from the GCG software package (Edelman et al., 1995). Further adjustments of the alignment were done manually to increase similarity, using sequence editors LINEUP (GCG package) and GENEDOC (Nicholas and Nicholas, 1997). A consensus ITS region sequence from the ingroup species was extracted and checked against the Ribosomal Database Project, and it showed the highest similarity with Arabidopsis thaliana. The alignment of these two sequences was useful to determine the boundaries of the coding and spacer regions for Limonium ITS sequences.

Determination of secondary structure Secondary structures of ITS-1 and ITS-2 were explored using the minimum free-energy algorithm (Zuker, 1989) with the program MFOLD in the GCG package. The ITS-1 Limonium consensus sequence was folded at $37^{\circ} \mathrm{C}$. Structures within $2.9 \mathrm{kcal} / \mathrm{mol}$ of the optimal structure were recovered using the Squiggles option in PLOTFOLD (GCG). The general model of angiosperm ITS-2 secondary structure proposed by Hershkovitz and Zimmer (1996) was employed to infer a consensus secondary structure model for the ITS-2 region of Limonium.

Compensatory mutations may be necessary to maintain the seemingly functional ITS secondary structures (Aimi et al., 1992; van der Sande et al., 1992; van Nues et al., 1994). Potential nonindependence of characters due to these compensatory mutations should be considered in phylogenetic analysis. Positional downweighting of the nonindependent positions provides a method to correct for this but the extent of such correlation must be determined empirically (Baldwin et al., 1995). We have performed the $\chi^{2}$-test proposed by Dixon and Hillis (1993) for character state weighting.

Data analysis. Several phylogenetic and statistical methods were followed to analyze the ITS sequence data. First, Felsenstein's (1981) maximum likelihood model was employed to reconstruct the phylogeny of section Limonium using the program FASTDNAML (OIsen et al., 1994). The empirical transition/transversion (ts/tv) ratio calculated as an average over all sequences gave a value of 1.5. Nevertheless, the best tree was searched for using a range of ts/tv ratios from 0.5 to 4.0 as input for the program and using global branch swapping (N1 = 21) and random addition of taxa.

Based on the selection guidelines set forth by $\mathrm{Nei}$ (1991), we chose the Jukes and Cantor (J C) oneparameter method (J ukes and Cantor, 1969) to calculate pairwise nucleotide divergence values for all sequences using the program DNADIST from the PHYLIP package (F elsenstein, 1993), as divergence values were in general lower than 0.05 substitutions/site for all ingroup species (Nei, 1991; Kumar et al., 1993). To minimize information loss, gaps and missing data were deleted only on a pairwise basis. A neighbor-joining dendrogram was constructed from the J C distance matrix. Bootstrap values for the different nodes were calculated after 1000 replicates.

Finally, PAUP 3.1 (Swofford, 1993) was employed to conduct parsimony analyses with and without considering compensatory mutations. Ambiguities were considered as polymorphisms or partial uncertainties but the topologies obtained were exactly the same using both alternatives, with the trees differing only in their length, as expected (Swofford, 1993). We report only the results obtained when they were considered as partial uncertainties. The heuristic search option was employed following the same strategy as in the previous section. A $50 \%$ majority rule consensus tree was constructed from all most-parsimonious trees. All trees were unrooted and rooted later using L. sinuatum as outgroup based on the results from ITS pairwise divergence values.

The previous phylogenetic reconstruction methods did not consider insertion-deletion (indel) mutations. Because some length variation was present in the ITS alignment, the effect of indels on evolutionary change of DNA sequences was al so investigated. Gaps were scored as additional presence-absence characters (Brunsfeld et al., 1992; Swofford, 1993; Baldwin et al., 1995) and, by adding this additional set of characters from indel data to the sequence data matrix, parsimony analysis was performed as above.

Neither bootstrap analysis nor the near-MPT method (Doyle and Doyle, 1993) were accomplished in parsimony analyses as computer memory limits were reached before completion. I n order to evaluate the nonrandom structure of the data sets, the skewness coefficient, gl, 
of Hillis (1991) was used as previously described. One-thousand random trees were generated to establish the significance of the gl coefficient.

\section{RESULTS}

\section{Chloroplast DNA Variation}

Intraspecific cpDNA polymorphism was observed only in pooled DNA from the Cabo de las Huertas population of $L$. furfuraceum, a sexual species $(2 n=18)$. This variation was diagnosed by two distinct RFLP patterns, of different intensity, with several probe-enzyme combinations. This polymorphism was analyzed in more detail to check whether it existed at the intra- or the interindividual level and whether it was present only in this population or also in other populations of this species. Hence, DNA from 10 individuals of the Cabo delas Huertas population and from a sample of 10 individuals from the Santa Pola population, situated 20 $\mathrm{km}$ apart from the previous one, were isolated separately and characterized for those probe-enzyme combinations that showed polymorphism in the Cabo de las Huertas population. Six individuals from the Cabo de las Huertas population presented $\mathrm{L}$. furfuraceum cpDNA haplotype A, and the rest had haplotype B, while individuals from the Santa Pola population showed pattern A for all probe-enzyme combinations, except one, which rendered a slightly different pattern and was excluded from the analyses. Consequently, a total of 15 different cpDNA haplotypes, obtained from the 14 Limonium species investigated, were subjected to further analyses.

A total of 779 different restriction fragments were scored, of which 490 were variable and 339 were parsimony informative. The numbers of bands shared by each pair of haplotypes are represented in Table 2.
The cpDNA data were strongly left-skewed, with gl of approximately -2.0 ( $P \ll 0.001)$, indicating a high phylogenetic information content of the entire data set (but see Hillis and Huel senbeck, 1992).

Wagner parsimony analysis identified three mostparsimonious trees with length of 654 steps, consistency index $(\mathrm{Cl})$ of 0.765 (with autapomorphies), and retention index $(\mathrm{RI})$ of 0.796 . The two other different character state transformational weight methods rendered identical MPT topologies, which were also coincident with the $50 \%$ majority-rule consensus Wagner tree, except that $L$. caesium and the $L$. narbonense-L. vulgare clade formed a polytomy in the majority-rule tree. In addition, the topol ogies of near-MPTs included the three alternative topologies from the Wagner analysis. Figure 2 shows the MPT obtained using the stepmatrix 21:19. The basal nodes of these trees are highly resolved. L. caesium, chosen as the outgroup species because it bel ongs to another section of the genus, is in fact situated basal to most species from section Limonium. However, L. narbonense and L. vulgare, from subsection Genuinaein section Limonium, form a basal monophyletic group, sister to the rest of the species of the section and to $L$. caesium. The mean number of bands shared by these two species with the rest is 259.08 (Table 2), around 100 fewer bands than those shared between pairs of the other ingroup species. Also, the average number of bands shared by $L$. caesi um with these species is higher (269.64) than with L. narbonense and L. vulgare L. angustebracteatum is sister to the clade formed by the remaining ingroup species, which form two relatively well-resolved monophyletic groups. L. rigualii, L. furfuraceum haplotype A, and L. cavanillesii form the first one, and the second comprises the remaining species. Among them, only the

\section{TABLE 2}

Number of Bands Shared between Each Pair of Limonium Species Generated by Restriction Analysis of cpDNA

\begin{tabular}{|c|c|c|c|c|c|c|c|c|c|c|c|c|c|c|c|}
\hline & Lnar & Lvul & Lduf & Lcam & Lgym & Lde & Lang & Lrig & Lvir & Lfur B & LfurA & Lten & Ldic & Lcae & Lcav \\
\hline L. narbonense & $115 / 368$ & 114 & 78 & 79 & 79 & 78 & 83 & 81 & 77 & 78 & 80 & 78 & 80 & 88 & 83 \\
\hline L. vulgare & 358 & $118 / 367$ & 79 & 80 & 80 & 79 & 84 & 82 & 78 & 79 & 81 & 79 & 81 & 80 & 84 \\
\hline L. dufourii & 256 & 258 & $119 / 365$ & 116 & 116 & 116 & 107 & 109 & 113 & 117 & 105 & 118 & 115 & 91 & 106 \\
\hline L. camposanum & 258 & 260 & 358 & $120 / 366$ & 119 & 117 & 107 & 108 & 113 & 116 & 105 & 117 & 114 & 90 & 105 \\
\hline L. gymnesicum & 259 & 261 & 358 & 365 & $120 / 366$ & 117 & 107 & 108 & 112 & 116 & 105 & 117 & 114 & 90 & 105 \\
\hline L. delicatulum & 257 & 259 & 353 & 359 & 360 & $120 / 365$ & 108 & 109 & 112 & 117 & 105 & 118 & 115 & 89 & 106 \\
\hline L. angustebract. & 259 & 261 & 328 & 330 & 331 & 332 & $118 / 357$ & 109 & 103 & 107 & 105 & 108 & 106 & 86 & 107 \\
\hline L. rigualii & 258 & 260 & 340 & 344 & 345 & 343 & 337 & $121 / 365$ & 105 & 108 & 117 & 109 & 107 & 88 & 118 \\
\hline L. virgatum & 258 & 260 & 345 & 352 & 353 & 350 & 328 & 338 & $116 / 362$ & 113 & 103 & 114 & 111 & 90 & 102 \\
\hline L. furfuraceumB & 260 & 262 & 352 & 359 & 360 & 356 & 330 & 341 & 350 & $120 / 372$ & 104 & 119 & 116 & 90 & 105 \\
\hline L. furfuraceumA & 257 & 259 & 332 & 336 & 337 & 335 & 331 & 354 & 332 & 349 & $118 / 365$ & 105 & 103 & 87 & 114 \\
\hline L. tenuicaule & 257 & 259 & 354 & 360 & 361 & 358 & 333 & 344 & 354 & 358 & 338 & $120 / 366$ & 117 & 91 & 106 \\
\hline L. dichotomum & 256 & 258 & 345 & 351 & 352 & 350 & 330 & 340 & 347 & 351 & 335 & 355 & $120 / 365$ & 94 & 108 \\
\hline L. caesisum & 264 & 266 & 271 & 271 & 272 & 273 & 272 & 270 & 267 & 271 & 267 & 271 & 267 & $124 / 365$ & 91 \\
\hline L. cavanillesii & 261 & 263 & 327 & 331 & 332 & 331 & 336 & 350 & 328 & 331 & 347 & 334 & 330 & 274 & $121 / 361$ \\
\hline
\end{tabular}

Note. Bands generated with four-cutters are shown in the upper hemimatrix, and those generated by six-cutters in the lower hemimatrix. The main diagonal shows the number of bands (four-cutters/six-cutters) for each species. 


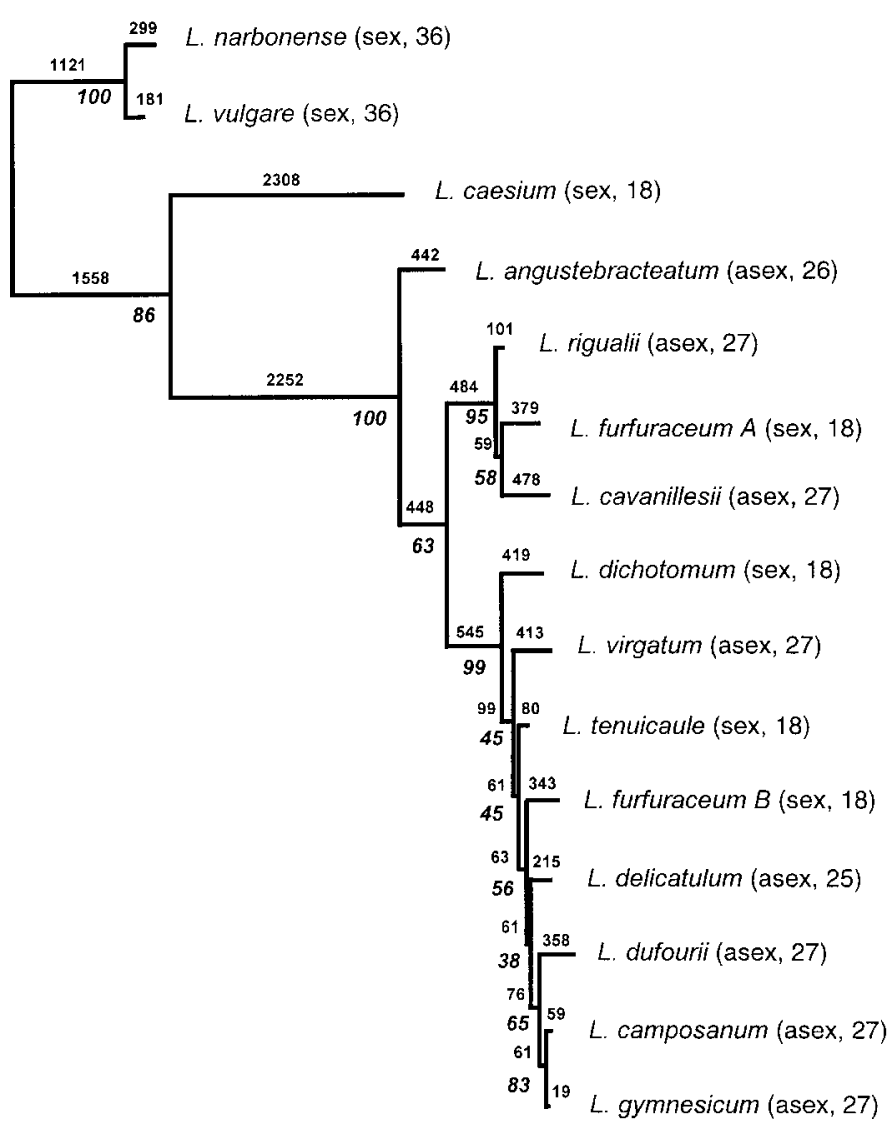

FIG. 2. Maximum parsimony tree derived from "enhanced Wagner" parsimony analysis using the step-matrix 21:19. Numbers al ong the branches represent mutational steps and those below are bootstrap values for each clade. This topology is identical to that of the NJ tree. Reproduction system (sex, sexual; asex, asexual, apomictic) and number of chromosomes are indicated between parentheses next to each species. nodes corresponding to L. dichotomum and L. gymnesicum-L. camposanum have high bootstrap support.

The NJ tree derived from the pairwise genetic distance matrix of restriction fragment data (Table 3) renders a topology identical to that of the weighted parsimony analysis (Fig. 2). Divergence values ranged from 0.0003 to 0.0229 . The extreme values of this range are due, on the lower side, to L. camposanum and L. gymnesicum, two highly related species from Mallorca included in subsection Densiflorae, which always form a monophyletic group. The upper value corresponds to the typical level of divergence of the species from subsection Genuinae, L. narbonense and L. vulgare, with respect to the other species (mean 0.0219), including L. caesium. However, L. caesium had levels of pairwise divergence with all the other ingroup species in the range 0.0176-0.0196, despite being the outgroup. Levels of divergence among the other ingroup species ranged from 0.0010 to 0.0066 . It is remarkable that the pairwise divergence between $L$. furfuraceum $A$ and $B$ hapl otypes is in the middle of this range.

Based on these cpDNA RFLP results, the current classification of section Limonium may be questioned, as divergence levels of $L$. narbonense and $L$. vulgare with other species of the same section were similar to those obtained with the outgroup species. Consequently, we decided to include as possible outgroups for the analysis of the nuclear ITS region threespecies that are classified under other sections of the genus, $L$. sinuatum, L. Iobatum, and L. echioides (Table 1). Other species included in the ITS study, and for which cpDNA was not studied, correspond to a separate study on L. interjectum, a presumed hybrid species, and to $\mathrm{L}$. cossonianum $(2 n=16)$ and $L$. minutum $(2 n=18)$, two diploid, sexually reproducing species with differing basic chromosome numbers.

TABLE 3

Distance Matrix Obtained Using Nei and Miller (1990) Procedure to Combine Four- and Six-Cutter Restriction Enzyme F ragment Analysis of cpDNAs from Limoni um Species

\begin{tabular}{|c|c|c|c|c|c|c|c|c|c|c|c|c|c|c|c|}
\hline & Lnar & Lvul & Lduf & Lcam & Lgym & Ldel & Lang & Lrig & Lvir & LfurB & LfurA & Lten & Ldic & Lcae & Lcav \\
\hline L. narbonense & 0.0000 & & & & & & & & & & & & & & \\
\hline L. vulgare & 0.0015 & 0.0000 & & & & & & & & & & & & & \\
\hline L. dufourii & 0.0229 & 0.0225 & 0.0000 & & & & & & & & & & & & \\
\hline L. camposanum & 0.0225 & 0.0221 & 0.0014 & 0.0000 & & & & & & & & & & & \\
\hline L. gymnesicum & 0.0223 & 0.0219 & 0.0014 & 0.0002 & 0.0000 & & & & & & & & & & \\
\hline L. delicatulum & 0.0228 & 0.0224 & 0.0020 & 0.0012 & 0.0011 & 0.0000 & & & & & & & & & \\
\hline L. angustebract. & 0.0209 & 0.0205 & 0.0059 & 0.0058 & 0.0056 & 0.0053 & 0.0000 & & & & & & & & \\
\hline L. rigualii & 0.0222 & 0.0217 & 0.0047 & 0.0044 & 0.0043 & 0.0043 & 0.0045 & 0.0000 & & & & & & & \\
\hline L. virgatum & 0.0223 & 0.0219 & 0.0030 & 0.0022 & 0.0022 & 0.0025 & 0.0061 & 0.0051 & 0.0000 & & & & & & \\
\hline L. furfuraceum B & 0.0227 & 0.0222 & 0.0024 & 0.0018 & 0.0016 & 0.0020 & 0.0062 & 0.0052 & 0.0028 & 0.0000 & & & & & \\
\hline L. furfuraceum $A$ & 0.0223 & 0.0219 & 0.0062 & 0.0057 & 0.0056 & 0.0058 & 0.0057 & 0.0017 & 0.0060 & 0.0044 & 0.0000 & & & & \\
\hline L. tenuicaule & 0.0229 & 0.0224 & 0.0016 & 0.0011 & 0.0010 & 0.0012 & 0.0052 & 0.0043 & 0.0018 & 0.0015 & 0.0054 & 0.0000 & & & \\
\hline L. dichotomum & 0.0227 & 0.0222 & 0.0032 & 0.0026 & 0.0025 & 0.0026 & 0.0059 & 0.0050 & 0.0030 & 0.0027 & 0.0061 & 0.0017 & 0.0000 & & \\
\hline L. caesium & 0.0201 & 0.0195 & 0.0183 & 0.0186 & 0.0185 & 0.0184 & 0.0184 & 0.0191 & 0.0188 & 0.0190 & 0.0197 & 0.0185 & 0.0186 & 0.0000 & \\
\hline L. cavanillesii & 0.0210 & 0.0206 & 0.0067 & 0.0064 & 0.0062 & 0.0062 & 0.0047 & 0.0020 & 0.0067 & 0.0067 & 0.0028 & 0.0058 & 0.0060 & 0.0177 & 0.0000 \\
\hline
\end{tabular}




\section{ITS Region Variation}

Aligned sequences of ITS-1 and ITS-2 were obtained for all species classified under section Limonium and the outgroup species with 488 characters in all (Fig. 3). The length of the ITS- 1 and ITS- 2 regions varied from 192 to $214 \mathrm{bp}$ and from 233 to $250 \mathrm{bp}$, respectively. M ost of the length variation encountered is due to small insertion-deletion events of only 1 or $2 \mathrm{bp}$. Only the outgroup species, especially L. sinuatum and L. lobatum, have larger indels (of up to 8 bp in ITS-2).

Among the 26 populations from the 21 Limonium species studied, 26 different ITS sequence types were identified. Although some level of uncertainty/polymorphism was detected in several species, this prevented the identification of a unique sequence only in $L$. del icatulum, a triploid species ( $2 n=25$; Table 1$)$. Hence, DNA from three individuals of this species was amplified, cloned, and sequenced. Six different ITS sequences, two from each individual studied, were obtained from eight clones. The two sequences derived from each individual differed in several indels, which prevented the direct sequencing of PCR products. Most of the ITS-2 sequence of $L$. cossonianum is missing due to problems in obtaining material. A single ITS type

$\begin{array}{lllllll}1 & 1111111111 & 1111111111 & 1111111111 & 1111122222 & 2222222222 & 2222222222\end{array}$ $\begin{array}{llllllllllll}11111 & 2222234445 & 5556666777 & 7778889990 & 0111122244 & 4555666667 & 7777788889 & 9999900000 & 0111222222 & 2223333333\end{array}$ $14679013890237823792 \quad 3792389123 \quad 5680391681 \quad 90129136569037267890 \quad 1346712461 \quad 3678901567 \quad 9028123456 \quad 7890123 \leq 57$

L. delicatulum-3
L. delicatulum-23
L. delicatulum-16
L. delicatulum-7
L. delicatulum-24
L. delicatulum-17
L. virgatum
L. cavanillesil
L. camposanum
L. tenuicale
L.narbonense
L. vulgare
L. angustebract.
L. caesium
L. rigualii
L. dichotomum
L. dufourii
L. Eurfuraceum
L.girardianum
L.gymesicum
L. interjectum
L. cossonianum
L.minutum
L. echioides
L. Lobatum
L. Sinuatum

\begin{tabular}{|c|c|c|c|c|c|c|c|c|c|}
\hline & & & & & & & & & \\
\hline & & & (2) & 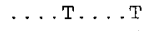 & & & & & \\
\hline. $\mathrm{CC}$. & $\ldots \ldots$ & $\ldots \ldots \mathrm{A}$ & $\ldots \ldots \ldots$ & $\ldots \mathrm{T} \ldots \mathrm{T}$ & $G \ldots \ldots$ & T. & $\mathrm{T} \ldots \ldots \ldots$ & 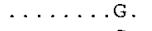 & \\
\hline $\mathrm{G} \ldots \mathrm{CC}$. & $\ldots \ldots \ldots$ & $\ldots$ T. . A & $\ldots \ldots \ldots$ & $\ldots \mathrm{T} \ldots \mathrm{T}$ & G. & $\mathrm{T}$ & $\mathrm{T} \ldots \ldots$ & 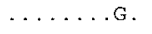 & \\
\hline & $\because$ & $\ldots \ldots$ & $\cdots \cdots \cdots$ & $\ldots \ldots \ldots$ & & & & & \\
\hline & $\cdots$ & $\cdots$ & $\cdots$ & $\cdots$ & & & & & \\
\hline & $\cdots$ & $\cdots \cdot$ & $\ldots \ldots$ & $\ldots \ldots \ldots$ & & & $\cdots$ & & \\
\hline$\ldots \mathrm{CC}$. & $\ldots \ldots \ldots$ & & $\ldots$ & $\ldots \ldots$ & & $\cdots$ & 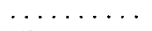 & $\cdots$ & $\cdot$ \\
\hline .MS. & $\cdots$ & $W$ & $\ldots \ldots$ & ...T.C..W & & R. . &.$Y$. & 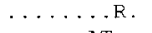 & $\cdots \cdots$ \\
\hline$\cdots$ & $\ldots Y$ & $y \ldots \ldots$ & $G \ldots \mathrm{Y}$ & $\ldots \ldots \ldots$ & $\cdots$ & $\ldots \mathrm{T}$ & $\cdots$ & 2 & $\ldots$ \\
\hline & $\cdots$ & & & re $>2+2$ & & & & $\cdots \cdots$ & \\
\hline 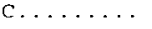 & A. & .A. & re $>2+2$ & $\cdots$ & & $\Gamma$ & . & . & $\cdots$ \\
\hline$\cdots \cdots$ & T.A. & $\ldots \mathrm{T} \ldots \mathrm{A}$ & $\cdots$ & CA. . . . GT & $G \ldots$ & $\ldots \mathrm{GT}$ & $\ldots \mathrm{G}$ & $\cdots$ & . \\
\hline R. & • & $\ldots \ldots \ldots$ & $\ldots \ldots$ & $\ldots S \ldots \ldots w$ & & . S & & AT. . & \\
\hline$\cdots$ & & $\mathrm{A}$ & & $\cdots$ & . & $\mathrm{T}$ & . TC. & 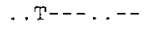 & \\
\hline & & & & . & & $\cdots$ & & & \\
\hline & . & & & $\cdots$ & & $\cdots$ & & . & \\
\hline$=$ & & • & & $\cdot$ & & $\cdots$ & 1. & & \\
\hline & & & & & & & & & \\
\hline$G \ldots . . M$ & $\ldots \ldots \ldots$ & K. . .W. & $\cdots$ & $\ldots$....Y.W & N. . & $\cdots$ & $\cdots$ & & \\
\hline & & & & & & & & & \\
\hline & $\cdots \cdots$ & $\cdots$ & & $\mathrm{T}$ & & & . & & \\
\hline & & & & & & & & & \\
\hline & & & & & -- & & & & $\mathrm{T}^{2}$ \\
\hline & & 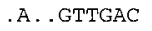 & $T \cdot T-T$ & & --.0 & & & & A.A.C.AT \\
\hline
\end{tabular}

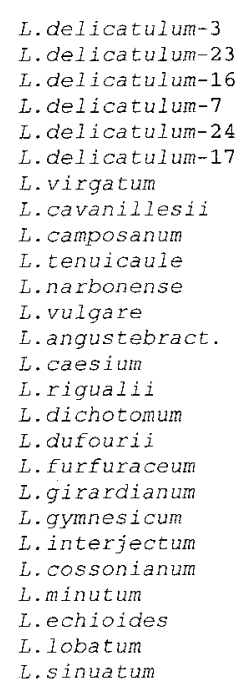

\begin{tabular}{|c|c|c|c|c|c|c|c|c|c|}
\hline & & & & & & & & & \\
\hline 45555 & 6677 & 7777888889 & 9990 & 22233334 & 4556677788 & 8899000000 & 1111222222 & 2344444444 & 57788 \\
\hline 56894567 & 901237802 & 3789234893 & $\leq 563457813$ & 6835724585 & 7563826712 & 3528035678 & 0379024567 & 9401345678 & 91303414 \\
\hline CTT-A-TCCT & ATTTGGGTAC & $\overline{\text { GC-AGATTCT }}$ & $\overline{\mathrm{ATG}} \overline{\mathrm{CGGCGT}}$ & $\overline{\text { GTCTGCACAA }}$ & TTCTGCGCCA & AAATATCCGC & CATGCAGAGG & AGATGAATCT & GCCGTTAA \\
\hline & $\ldots$ T.A. & $\ldots G \ldots A \ldots$ & $\ldots$ T.A.C & $\ldots \ldots$ & $\ldots \ldots \ldots$ & $\ldots \ldots \ldots \mathrm{T}$ & . & .A. . . ATC & \\
\hline & $\ldots$ T.A. & $\ldots$ G. A. . & $\ldots$....$C$ & & $\ldots$ T..... & & & . A. . . ATC & ... \\
\hline & ...T.A. & $\ldots$ G. A. . & $\ldots$ T.A. C & & & $\ldots \mathrm{T}$ & & . А. ... ATC & .T..... \\
\hline ????????? & $\ldots$ & $\ldots \ldots \ldots$ & ...A... & & & $\ldots \ldots A$ & & $\ldots$ & \\
\hline ????????? & & & & & & $\ldots \ldots$. & & & \\
\hline ????????? & & $\mathrm{T} \ldots \ldots$ & $\ldots$. & & C...T & $\ldots \ldots$. & & & .. \\
\hline & & . $\ldots \ldots \ldots$ & $\ldots \mathrm{H}$ & & $\ldots Y \ldots \ldots$ & . R. & & A.... & \\
\hline.$Y$. & $\ldots$ K.R. . & $\ldots R \ldots$. & ...Y.R.Y & & $\ldots$ & $\ldots Y$ & & A. . . AYC & . Y. ???? \\
\hline & & T. . . . . & & & $\ldots$. Y . . & & $\mathrm{T}$. & ....????? & ???????? \\
\hline & & $\cdots \cdots$ & & & & & & $\ldots \ldots$ & ???????? \\
\hline . CCTT. . GT. & ..GT.A..A & T..G. & $\ldots A . G$ & T...T.T. & $\ldots T \ldots T$ & $\ldots$ TG . A. .T &. $\mathrm{C} \cdot \mathrm{G}$. & . АTC . . .TC & TTTAC... \\
\hline . CCTT . .GT. & . CT.A.A & T..G.... & $\ldots$. A.TG & T..T.T. & C...T. & $\ldots$ TG. T. T & .C.G. & ATC. & TTTAC. . \\
\hline$Y \ldots \ldots \ldots$ & $\ldots \ldots \ldots$ & .YG . . . . . & ..A.R... & & $\ldots \ldots \ldots$ & $\ldots \ldots Y \ldots Y$ & $\ldots \ldots$ & . R... & $\ldots \ldots$ A?? \\
\hline$C \ldots \ldots$ & $\ldots C T \cdot A . T$ & . G. & .T.A. & A & & - T. TT. & T... T. T. & . AT . . GATC & . T.... \\
\hline 8 & & & & & & & Y. & $\ldots . c$ & R. \\
\hline &. $\mathrm{C}$ & & G. & & & . & $\ldots \ldots \ldots$ & $\ldots \ldots w$ & . T.... \\
\hline & & 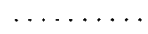 & & & $\ldots$. . T. & $\cdots$ & $\ldots \ldots$ & $\ldots \ldots w$ & $\ldots \ldots ? ?$ \\
\hline$\ldots \ldots$ CG . . & $\ldots$ & $\ldots \ldots \ldots$ & $\cdots$ & . TA. . & . & $\cdots$ & $\theta^{\circ}$ & & \\
\hline . C.... & $\ldots$ K.R. . & . .R. .Y. & \#.Т.А. & & . & $\ldots Y$ & & .A. . WWYC & .Y. . ???? \\
\hline$\cdots$ & $\ldots$ K. . . & ..RA.W... & $\ldots \ldots R \ldots$ & .. & $\cdots$ & $\ldots \ldots \ldots Y$ & $\cdots$ & A....??? & ???????? \\
\hline$\cdots \cdots$ & $\ldots \ldots \ldots$ & . T. . & \#.H. . R. & & & & & $\cdots$ & \\
\hline .C.C-... & . .C.A. . & .Y.S?????? & ?????????? & ?????????? & ?????????? & ?????? & ?????????? & ???? & ?? \\
\hline$\ldots$ GC $\ldots$ & $\ldots \ldots \ldots$ & $\ldots A-\ldots \ldots$ & $\ldots \ldots \ldots$ & $\cdots$ & $\ldots \ldots$ & . & & & \\
\hline TC. T. & . T. AM. A & G. & $\ldots$ A. A. . C & T... АT. T. & . TTT. & G. . T & G... & AT.A. AT. & TTA. \\
\hline - G. CGA. T. & . AGTT . CGA & AC. CTACTC & . CT. AATA. A & . CTG . CATG & C.T. TTATTT & TTTC.C. AT & .T.A.C.TTT & $\mathrm{C}-$. & $--\mathrm{CA} \cdot \mathrm{CC}$ \\
\hline.$-G$ & GTT. CGA & AC. CTACTC & .CT.AATA, A & . CTG . . CATG & . TCCPA. & TTC.C. . AT & . T.A.C. TTT & $\mathrm{C}-$. & $--\mathrm{CA} \cdot \mathrm{CC}$ \\
\hline
\end{tabular}

FIG. 3. Variable positions in the alignment (488 bp) of ITS-1 and ITS-2 sequences from the studied Limonium species. Six different sequences were obtained from L. delicatulum, denoted by the different clone numbers from which they were sequenced. Underlined positions indicate phylogenetically informative sites. The symbol "?" represents nonsequenced positions. 
was extracted from the other species surveyed. A consensus sequence was obtained from each population analyzed in the corresponding species. In those species for which more than one population was examined, the consensus sequence was identical in all the corresponding populations. Therefore, ambiguities shown in the alignment in Fig. 3 were present in all the sequences from the corresponding species.

ITS secondary structure and character weighting. The consensus secondary structure models for the ITS-1 and ITS-2 regions were obtained from the corresponding Limonium consensus sequences and compared with available models for angiosperms (Yeh and Lee, 1991; Liu and Schardl, 1994; Bakker et al., 1995; Hershkovitz and Zimmer, 1996). The relevant features described by these authors are also present in both Limonium ITS regions.

From the ITS-1 and ITS-2 secondary structure models, the observed number of single and double compensatory and noncompensatory mutations were calculated, excluding outgroup species and considering ambiguities as uncertainties and polymorphisms separately. Thetest proposed by Dixon and Hillis (1993) was highly significant ( $\chi^{2}$ values ranged from 14.9 to 54.0, df $=1, P<0.001$ ). After assuming a linear scaling, a relative weighting scheme of 0.8:1.0 for stem vs loop characters was chosen for further analyses, as opposed to equal character state weights. However, the results obtained did not differ significantly between both alternatives, and we present the results from only the equal weights analyses.

ITS sequencedivergence. Table 4 shows the average number of substitutions per site using J $C$ distance for ITS-1-ITS-2 sequences in pairwise comparisons. ITS sequence divergence values ranged from 0.000 to 0.283 substitutions/site. The highest value corresponds to the typical divergence between $\mathrm{L}$. sinuatum or L. I obatum and all the other species (average $=0.251$ ). Levels of divergence between $L$. narbonense and $L$. vulgare sequences with respect to the remaining species were around 0.11 substitutions/site. Pairwise comparison of $\mathrm{L}$. echioides with all the other ingroup species was slightly lower (approx 0.09). The average divergence was even lower, 0.06 , when L. caesi um was compared with these other ingroup species. When $L$. narbonense and $L$. vulgare were excluded, ITS divergence values for the ingroup species from section Limonium ranged from 0.00 to 0.05 . A null divergence was found between L. girardianum and L. cavanillesii. However, the identity percentage between these species was 92.2, and the discrepancy was due to differing ambiguous positions.

Intraspecific ITS pairwise divergence values among $\mathrm{L}$. delicatulum clones (Ldel) had range limits $(0.00$ to 0.05$)$ similar to interspecific values among the remaining ingroup species. Two major types of sequences were observed in this species: type $A$, in- cluding Ldel7, Ldel17, and Ldel24, with pairwise sequence variation ranging from 0.004 to 0.008 ; and type B, including Ldel3, Ldel 16, and Ldel23, whose range of pairwise variation was $0.000-0.008$. N ote that each clone pair Ldel7-Ldel3, Ldel17-Ldel 16, and Ldel23-Ldel24, was obtained from the same individual. Thesetwo ITS types present in each L. delicatulum individual are closely related to two diploid, sexual species, L. cossonianum (type B) and L. minutum (type A), with different base chromosome numbers, $n=8$ and $n=9$, respectively.

Phylogenetic analyses. Of the 488 aligned positions from the whole ITS region, 198 sites were variable, of which 156 were parsimony informative (Fig. 3). The skewness test (Hillis, 1991) suggested nonrandom structure in this data set $(\mathrm{gl}=-2.70$, $P \ll 0.01)$.

Maximum likelihood (ML) analysis of Limonium ITS sequences render ed exactly the same topologies for the different ts/tv ratios tested (from 0.5 to 4.0) with and without considering different character state weights (categories). However, the tree with the highest ML value (-2765.76) was that obtained for a ts/tv ratio of 1.0, without using categories (Fig. 4). Basal branches were all significantly different from zero. The group formed by all the other ingroup species apart from $L$. narbonense and L. vulgare was also well supported. Within this group there were only three significant branches, one corresponding to the terminal branch for L. furfuraceum. The two inner branches defined three groupings. The first group included L. cossonianum, L. cavanillesii, L . girardianum, and the three L. delicatulum type B sequences. The second group was composed of L. gymnesicum and L. virgatum. The third group included all the remaining species.

The NJ dendrogram derived from the J C distance matrix of Table 4 had the same topology as the one obtained by ML (Fig. 4), differing only in the support for some branching nodes. Bootstrap values were high at the basal nodes of the tree, involving outgroup species and the sister species $L$. narbonense and L. vulgare. The other ingroup species formed a monophyletic group with a bootstrap support of $82 \%$. There were two well-supported subgroups within this group. The first subgroup was formed by L. delicatulum ITS type B sequences (with $87 \%$ bootstrap value). This subgroup is joined to other ingroup species, L. girardianum, L. cavanillesii, L. gymnesicum, and L. cossonianum, with bootstrap values lower than $50 \%$, and to L. virgatum with $68 \%$ bootstrap support. The other subgroup was supported by a bootstrap value of $87 \%$ and included the remaining species analyzed, coincident with the last subgroup described for the ML tree. Here, only the nodes corresponding to the clade formed by two $L$. delicatul um ITS type A sequences and L. mi nutum had bootstrap supports higher than $50 \%$. 
TABLE 4

Average Number of Pairwise Substitutions per Site $\left(\times 10^{-2}\right)$ Using J ukes and Cantor Distance for the ITS Region Sequences of Limonium Species

Lvir Lcav Lcam Lten Lnar Lvul Lang Lcae Lrig Ldic Lduf Lfur Lgir Lgym Lint $\quad$ Ld $3 \quad$ Ld 23 Ld $16 \quad$ Ld $7 \quad$ Ld $24 \quad$ Ld $17 \quad$ Lcos $\quad$ Lm Lech Llob

L. virgatum

L. cavanillesii

L. camposanum
L. tenuicaule

L. narbonense

L. vulgare

L. angustebract.

L. caesium

L. rigualii

L. dichotomum

L. dufourii

L. furfuraceum

L. girardianum $\overline{0 .}$

$0.010-$

$0.023 \quad 0.020-$

$\begin{array}{llll}0.020 & 0.013 & 0.010 & -\end{array}$

$\begin{array}{ccccc}0.155 & 0.136 & 0.155 & 0.150 & - \\ 0.163 & 0.145 & 0.164 & 0.159 & 0.011\end{array}$

$\begin{array}{llllll}0.014 & 0.012 & 0.007 & 0.005 & 0.144 & 0.153\end{array}$

$\begin{array}{lllllll}0.080 & 0.058 & 0.084 & 0.083 & 0.152 & 0.155 & 0.073\end{array}$

$\begin{array}{llllllll}0.018 & 0.017 & 0.005 & 0.005 & 0.155 & 0.164 & 0.007 & 0.084\end{array}$

$\begin{array}{lllllllll}0.019 & 0.015 & 0.015 & 0.008 & 0.161 & 0.170 & 0.012 & 0.087 & 0.009\end{array}$

$\begin{array}{lllllllllll}0.016 & 0.015 & 0.018 & 0.010 & 0.157 & 0.165 & 0.012 & 0.085 & 0.009 & 0.010\end{array}$

$\begin{array}{llllllllllllll}0.012 & 0.000 & 0.020 & 0.012 & 0.131 & 0.139 & 0.005 & 0.052 & 0.014 & 0.017 & 0.017 & 0.021\end{array}$

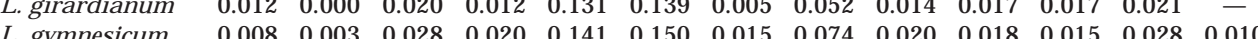

$\begin{array}{lllllllllllllllll}\text { L. interjectum } & 0.016 & 0.017 & 0.007 & 0.005 & 0.158 & 0.166 & 0.002 & 0.083 & 0.005 & 0.009 & 0.009 & 0.011 & 0.012 & 0.020\end{array}$

$\begin{array}{lllllllllllllllll} & \\ \text { L. delicatulum 23 } & 0.039 & 0.010 & 0.061 & 0.053 & 0.150 & 0.158 & 0.045 & 0.074 & 0.058 & 0.050 & 0.050 & 0.065 & 0.009 & 0.012 & 0.055 & 0.004\end{array}$

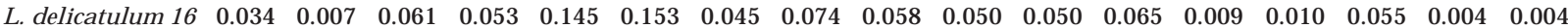

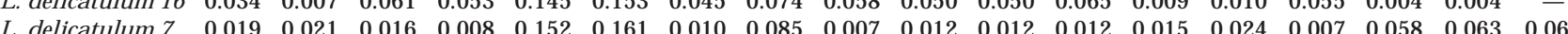

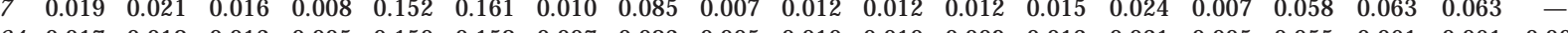

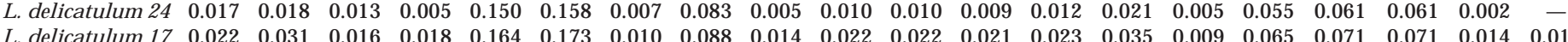

$\begin{array}{llllllllllllllllllllllll}\text { L. delicatulum } 17 & 0.022 & 0.031 & 0.016 & 0.018 & 0.164 & 0.173 & 0.010 & 0.088 & 0.014 & 0.022 & 0.022 & 0.021 & 0.023 & 0.035 & 0.009 & 0.065 & 0.071 & 0.071 & 0.014 & 0.012 & - & -0.025 & \\ \text { L. cossonianum } & 0.051 & 0.021 & 0.072 & 0.063 & 0.171 & 0.181 & 0.038 & 0.074 & 0.059 & 0.058 & 0.042 & 0.067 & 0.021 & 0.025 & 0.062 & 0.024 & 0.024 & 0.029 & 0.059 & 0.059 & 0.064 & -\end{array}$

$\begin{array}{llllllllllllllllllllllllll}\text { L. minutum } & 0.018 & 0.019 & 0.015 & 0.007 & 0.155 & 0.163 & 0.012 & 0.086 & 0.004 & 0.012 & 0.012 & 0.013 & 0.017 & 0.023 & 0.007 & 0.053 & 0.058 & 0.058 & 0.002 & 0.000 & 0.012 & 0.054 & 0.12\end{array}$

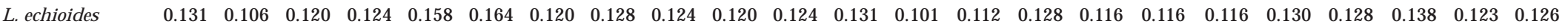

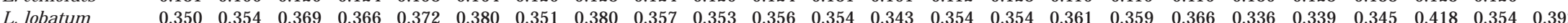

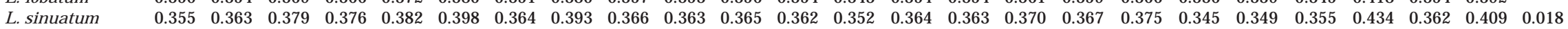


Wagner parsimony analysis from the ITS data matrix identified 17,567 most-parsimonious trees, with length of 325 steps, and $\mathrm{Cl}$ and $\mathrm{RI}$ values of 0.824 and 0.860 , respectively. Despite the large number of MPTs, the consensus tree (Fig. 5) retained considerable resolution. For example, the basal relationships are coincident with those obtained in the previous analyses. Polytomies at inner branches were responsible for the large number of equally most-parsimonious trees encountered. However, the relationships among these ingroup species had features in common with those described above. In this analysis, L. cossonianum forms a clade with $\mathrm{L}$. delicatul um type $B$ sequences, which is not present in the previous analyses.

When parsimony analysis was performed with the additional data matrix of 43 presence-absence gap characters, the skewness index for the whole data set was -3.1 ( $P \ll 0.01)$. A total of 246 MPTs were obtained of 367 steps, with $\mathrm{Cl}=0.782$ and $\mathrm{RI}=0.825$. The

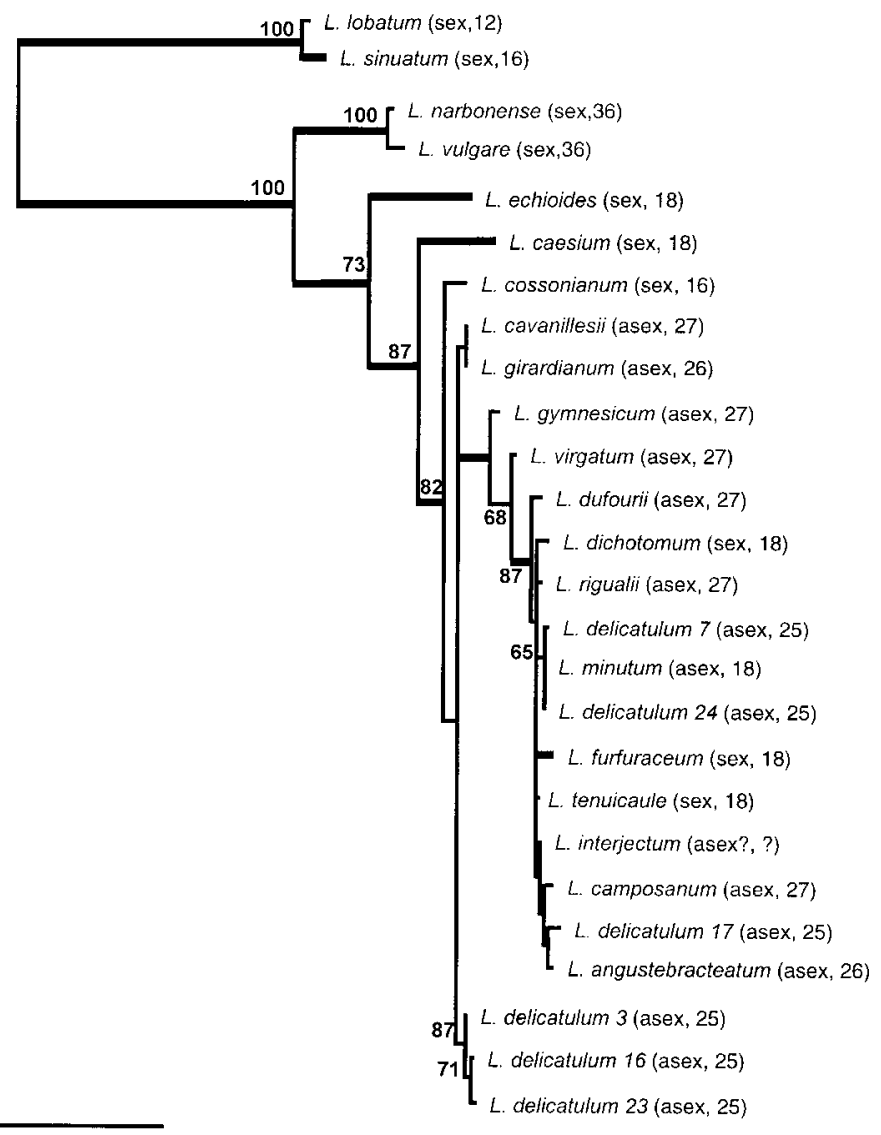

0.10

FIG. 4. Maximum likelihood tree derived from ITS sequence analysis of Limonium species. Thick branches are significantly different from zero length. Values above each node indicate bootstrap support higher than $50 \%$ for the corresponding branching point obtained with 1000 replicates using the neighbor-joining algorithm and J C estimate of nucleotide divergence. Reproduction system (sex, sexual; asex, asexual, apomictic) and number of chromosomes are indicated between parentheses next to each species.

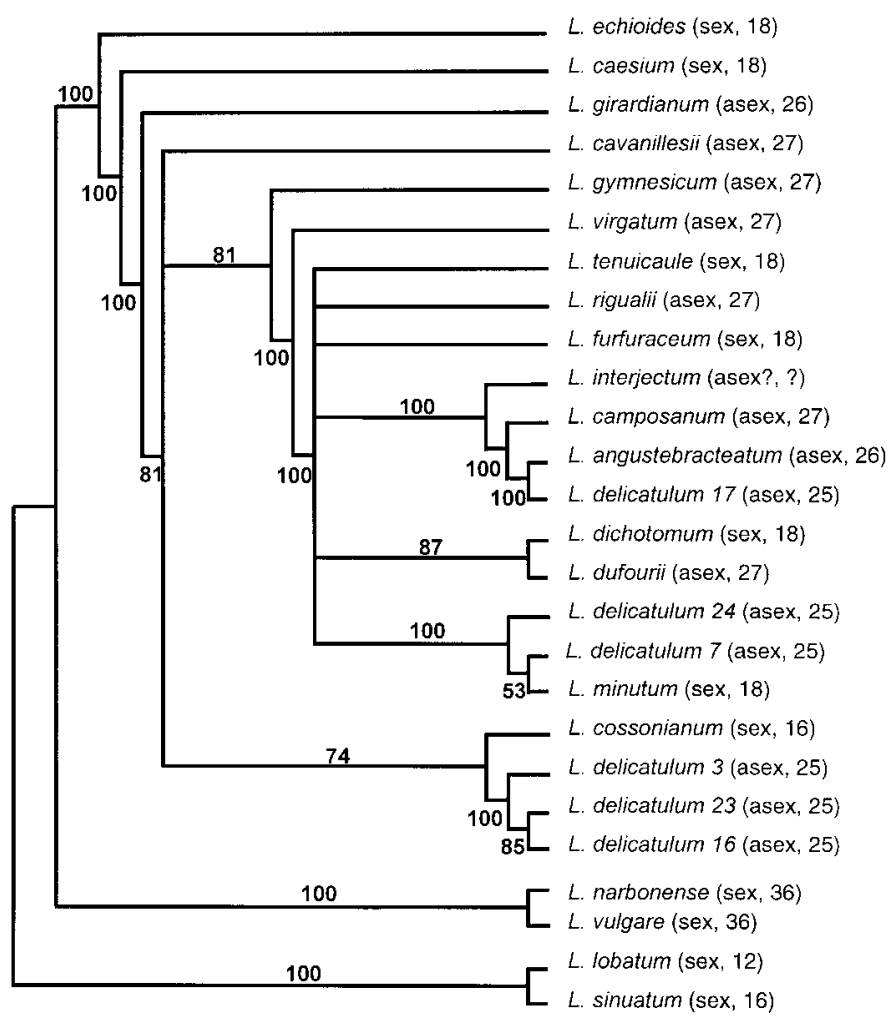

FIG.5. Majority-rule (50\%) consensus treefrom parsimony analysis of ITS sequences. Values next to each node correspond to the percentage of the 17,567 MP trees supporting it. Reproduction system (sex, sexual; asex, asexual, apomictic) and number of chromosomes are indicated between parentheses next to each species.

majority-rule consensus tree (not shown) obtained in this analysis was highly resolved not only at basal nodes but also at more internal branches. This topology showed basically the same relationships among Limonium species as in previous analyses, with most polytomies being coincident with those nodes in the $\mathrm{NJ}$ tree having low bootstrap support and the $\mathrm{ML}$ tree branches not significantly different from zero.

Sexually reproducing species. To gain some insight into the evolution of this group of species without the possibly disturbing effects of reticulate evolution, we performed the same analyses previously described on a subset of Limonium ITS sequences, those corresponding to the 11 sexually reproducing species indicated in Table 1 . In this case, the topologies obtained by the three phylogenetic reconstruction methods were identical. The ML tree (Fig. 6) presented most inner branches significantly different from zero. The two branches not differing from zero corresponded to the nodes with bootstrap support lower than $80 \%$ in the NJ and MP analyses. The MP analysis provided 15 equally MPTs, with 254 steps $(\mathrm{Cl}=0.890, \mathrm{RI}=0.887)$. The $50 \%$ majority-rule consensus for these 15 MPTs presented only one polytomy, coincident with one of the unsupported branches in the ML reconstruction, joining one out- 


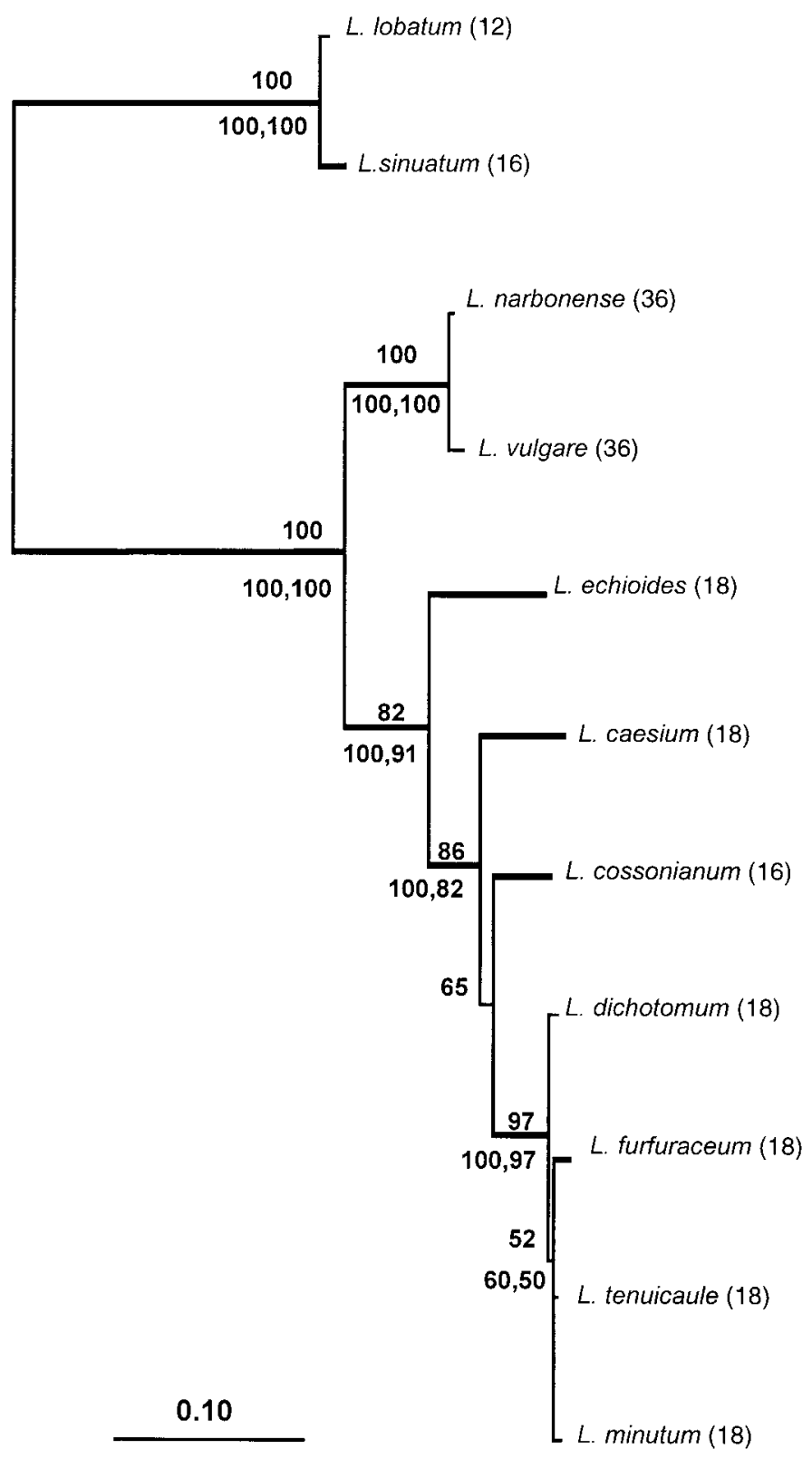

FIG. 6. Maximum likelihood tree obtained from ITS se quences of sexually reproducing Limonium species. Thick branches are significantly different from zero length. Values above each node indicate bootstrap support (higher than 50\%) for the corresponding branching point obtained with 1000 replicates using the neighbor-joining algorithm and J $\mathrm{C}$ estimate of nucleotide divergence. The tree topology is identical to 1 of the 15 mostparsimonious trees obtained with the same data set. Numbers bel ow each branch indicate the percentage of times the corresponding node appears in the 15 MP trees and in 1000 bootstrap replicates, respectively. The number of chromosomes is indicated between parentheses next to each species.

group species (L. caesium) to the other ingroup species (apart from L. narbonense and L . vulgare) bel onging to section Limonium. The same topology was obtained when only diploid species were analyzed in a similar way (results not shown).

\section{DISCUSSION}

Intraspecific Variation

We have detected intraspecific polymorphism in 21 species of Limonium with two molecular markers, RFLPS of chloroplast DNA and nuclear rDNA ITS sequences, despite the relatively small intraspecific sampling performed for most species. L. furfuraceum, a sexual species with a very conspicuous morphology and endemic to a small area in southeastern Spain, presented two different cpDNA haplotypes but no variability was found in its rDNA. Estimated sequence divergence between the two haplotypes $(0.44 \%)$ falls within the reported values for intraspecific cpDN A variation in angiosperms (Soltis et al., 1992). Moderate levels of cpDNA variation may therefore be present within Limonium species, which could have been overlooked due to the sampling strategy used in this study. However, this pattern of variation can be explained in other ways (e.g., Rieseberg and Brunsfeld, 1992). A likely explanation is that those individuals with cpDNA haplotype B obtained their cytoplasm by introgression from an unidentified Limoni um species (as hapl otypeA was also present in the other population of the species analyzed) but introgression would not have been suspected based only on nuclear DNA. A second possibility is that $\mathrm{L}$. furfuraceum is of recent hybrid origin and that it was formed by reciprocal crosses between two species with different cpDNAs. Thus, it could be argued that both ancestors acted as maternal progenitors but the offspring would have the same rDNA (perhaps the sum of both parents but see later). However, L. furfuraceum is a sexual, diploid species showing no signs of reduced pollen fertility or low seed production. A scenario involving diploid hybrid speciation has been invoked for several taxa of the related genus Armeria (Fuertes et al., 1999) but basic data on experimental hybrids in Limonium that could support this hypothesis are missing.

L. delicatulum represents another case in which intraspecific variability has been detected but with an opposite rDNA-cpDNA pattern of variability. This is an asexual species, with apomictic reproduction, endemic to the southeast of the Iberian Peninsula. Mertens (1993) summarized the possible explanations for this pattern of association in asexual polyploids formed through hybridization. The association of several rDNA genotypes with a single cpDNA haplotype could be explained if a single species with a distinct cpDNA haplotype were the maternal parent in all cases of hybridization, with the different ITS types from both parents. These might remain as different rDNA intraindividual arrays in the genome (Bobola et al., 1992). On the other hand, within-species polymorphism can be explained as a remnant of the polymorphism in the ancestral species or as due to the accumulation of 
mutations without further homogenization. In other Limonium species some ambiguities in rDNA sequences have been detected (Fig. 3) that could actually represent intraspecific polymorphisms. An apomictic reproductive system (Table 1 ) is correlated with ITS sequences showing more than 10 ambiguously scored positions (Fig. 3), with only a few exceptions to this rule: L. dufourii, L. interjectum, and L. virgatum presented fewer than 6 ambiguities. If the results obtained in the more detailed analysis of L. delicatuI um are similar for the other apomictic species and they actually represent polymorphic sites resulting from the simultaneous presence in each individual of two relatively divergent ITS sequence types, then it may be possible to determine the putative ancestral hybridizing species. Consequently, it will be necessary to investigate the levels of intraspecific and intraindividual variability in these species by a strategy similar to that followed with L. delicatul um.

In summary, intraspecific rDNA or cpDNA types of $L$. delicatulum and L. furfuraceum were paraphyletic. They showed levels of intraindividual (L. delicatulum) and intrapopulation (L. furfuraceum) divergence similar to those detected between other Limonium species, reinforcing the introgression or hybridization hypothesis for the origins of these taxa. Furthermore, when multigenefamilies arestudied, the special mechanisms involved in their evolution (unequal crossing over, gene conversion, etc.) may override the classical factors (selection, mutation, and genetic drift) as agents regulating genetic variation, resulting in unexpected variation patterns based on the biology of the species. These factors tend to homogenize orthologous and paralogous genome regions and can obscure the parental rDNA source, as could bethe case in L. furfuraceum. Although it has been demonstrated that these mechanisms are active in asexual species (Hillis et al., 1991; Crease and Lynch, 1991), they could fail to act on multicopy units contributed by the parental species if the hybridization event was recent and/or the rDNAs occur at different loci in the parental taxa and interlocus gene conversion was not operating (Baldwin et al., 1995). This could be the case in L. delicatulum. A similar explanation has been suggested for ITS polymorphism in other plant species (Suh et al., 1993; Karvonen and Savolainen, 1993; Campbell et al., 1997).

The results here reported illustratethe importance of analyzing intraspecific variability in studies of both cPDNA-RFLP and ITS sequences. In some cases, conspecific samples rendered identical genotypes; in others, intraspecific variability has been detected through pooled DNA samples from different individuals of the same population. These phenomena should prevent reporting these ITS sequences as unique sequences, representative of the corresponding species.

\section{Phylogeny Reconstruction}

The analysis of cpDNA using multiple methods of phylogenetic reconstruction has revealed a relatively stable phylogenetic structure. Weighted parsimony is considered the best choice among all parsimony methods for RFLP analysis (Albert et al., 1992; Felsenstein, 1992; Holsinger and J ansen, 1993; Huelsenbeck and Hillis, 1993). Although the selection of weights remains controversial (Swofford et al., 1996), those weights that correct for possible violations of the assumptions of the phylogenetic inference methods should be considered.

The presumed uniparental (maternal) inheritance of cpDNA in Limonium (Clegg, 1987; Harris and Ingram, 1991) and absence of intermolecular recombination prevent reticulation in cpDNA phylogenies. However, caution is needed in the interpretation of results in which lineage sorting, hybrid origin, or introgression may have resulted in the transfer of cpDNA from one lineage to another (Soltis et al., 1992; Doyle, 1992). In section Limonium, polyploidy and apomixis are common, numerous hybrids occur naturally, and, as a consequence, reticulate evolution seems to be the rule rather than the exception. Therefore, an a posteriori search of inconsistencies with other types of data is necessary before any conclusion on the phylogeny of these species can be drawn. This should preferentially be done from the nuclear genome since hybridization is less permeable to this biparentally inherited DNA (McDade, 1992).

Sizes of ITS-1 and ITS-2 in the Limonium species studied were similar to those reported for other flowering plants, with ITS-1 longer than ITS-2 (Baldwin et al., 1995). Within section Limonium, the ITS region has evolved primarily by point mutations, which conforms with other studies on closely related plants (Soltis and Kuzoff, 1995; Baldwin et al., 1995). The conservation of ITS sequences is presumably due to their role in the production of mature rRNA, and this functionality depends on evolutionarily conserved secondary structural motifs. Inference of nonindependence at directly opposing sites in these secondary structures can be determined empirically (Dixon and Hillis, 1993). However, in our case the use of differential character weights for stem vs loop positions did not lead to different results in the analysis of ITS sequences from Limonium. It has been demonstrated that rRNA processing mechanisms could be labile enough to allow readjustments of intrastrand RNA pairing, which could imply mutations at nonpaired positions (cryptic nonindependence) (Olsthoorn et al., 1994). This pattern of substitutions could have important implications for phylogenetic analysis but it could also mean that selection for compensatory mutations might be weaker for these spacers than for nrDNA coding regions, alleviating the concern about nonindependence of characters. 
None of the methods currently available for phylogenetic analysis is ideal, and it is advisable to use different approaches for data analysis (Holsinger and J ansen, 1993; Swofford et al., 1996). In this case, the relationships obtained among Limonium ITS sequences using $M L, N J$, and parsimony approaches are, in general, congruent for well-supported groups.

\section{Evolution in Limonium}

Several base chromosome numbers ranging from $\mathrm{n}=$ 6 to $n=9$ have been reported in Limonium (Erben, 1979). He suggested on the basis of chromosome morphology that in subgenus Limonium the chromosome number $n=8$ is not ancestral but was derived from $n=$ 9 karyotypes through chromosome fusion. Thus, only taxa with $\mathrm{n}=8$ have two long metacentric chromosomes in their diploid complement that are thought to have evolved from smaller ones present in the $n=9$ genomes. The position of $L$. cossonianum $(2 n=16)$ in the ITS phylogeny suggests that the $n=8$ karyotype is derived within section Limonium, as taxa having $\mathrm{n}=9$ appear basal in the nuclear phylogeny, supporting the hypothesis of chromosomal evolution by descending aneuploidy in section Limonium (Erben, 1979). The relationships of the remaining species suggest that the base chromosome numbers present in Limonium species could have changed morethan once in theevolutionary history of Limonium through similar cytological rearrangements.

The fact that two ITS types have been found within L. delicatulum is consistent with a predicted allopolyploid origin of a taxon having an odd chromosome number $(2 n=25)$. I nterestingly, one type of the nuclear sequences of $L$. delicatulum stands near $L$. cossonianum $(2 n=16)$, whereas the other shows a cl ose relationship with $L$. minutum $(2 n=18)$, suggesting that these or other closely related taxa could be involved in the formation of the triploid taxon. Thus, Erben's (1979) hypothesis on the origin of polyploid taxa in Limonium is supported for L. delicatulum by the phylogenetic analysis of the ITS data.

\section{Comparison of Phylogenetic Relationships and \\ Taxonomy in Limonium}

In the absence of a previous phylogenetic analysis of section Limonium based on other independent characters (although see Lledó et al., 1998), our results can be discussed only in relation to the current classification of the group, which is based mainly on morphological and karyological characters (Boissier, 1848; Pignatti, 1971; Erben, 1993). This is an important limitation (Donoghue and Cantino, 1988; Doyle et al., 1990), especially in cases of striking disagreements (Doyle and Doyle, 1993).

The current splitting of section Limonium does not agree with the results of the phylogenetic analyses of nuclear and organellar markers. In fact, they suggest that the largest section of the genus (section Limonium) does not constitute a monophyletic assemblage. The basal position of the two analyzed species of subsection Limonium (L. vulgare and L. narbonense) was strongly supported in all analyses. The same results were obtained using rbcL sequences with five Limonium species (Lledó et al., 1998). Levels of sequence divergence suggest that molecular differentiation between taxa of subsection Limonium and the other species from section Limonium is larger than expected based on exomorphic features. In addition, morphological and anatomical data suggest that subsection Limoni um is a group of well-knit species (Bokhari, 1973) not linked by intermediates to the remaining section Limonium. The distinctiveness of subsection Limonium is so remarkable that it should probably be granted a sectional status. Because $L$. vulgare is the type species of the genus (and hence of section Limonium), whatever nomenclatural rearrangement that could be proposed must also involve the other sectional names.

Although few sexual taxa belonging to subsections Hyal ol epidaeand Stei rocladaewere available for study, no clear distinction between them has arisen. This agrees with Bokhari's (1973) results based on anatomical and morphological features. He stated that the characters used by Boissier (1848) to separate subsections Hyalolepidae and Steiroclade were inefficient, and he suggested that these two subsections should be combined. Furthermore, he proposed that subsections Densiflorae and Dissitiflorae should be merged. This could not be directly addressed in this work since no sexual taxa from subsection Densiflorae could be analyzed and only one species from subsection Dissitiflorae was available. However, the combined analysis of sexual and apomictic taxa does not support the recognition of subsections Densiflorae and Dissitiflorae as natural segregates within Limonium. When diploid and polyploid taxa are analyzed together, none of the four subsections appears as monophyletic, al though interspecific hybridization may have blurred boundaries between distinct lineages. Nevertheless, Limonium taxa belonging to these four subsections are apomictic and, presumably, have a hybrid origin from ancestors belonging to either subsection. Therefore, there is little sense in recognizing them as distinct unless other hybrid subsections are created. Taking into account the great taxonomic complexity of the genus, this is clearly an unsatisfactory solution.

Members of sections Polyarthrion and Schyzymenium are successivesisters to section Limonium (excluding L. narbonenseand L. vulgare) but their monophyly should be checked by the analysis of additional taxa and markers. L. caesi um has been excluded sometimes from subgenus Limonium [recognized by some authors and included with other species within subgenus Si phonantha (Pau, 1898) or Myriolepis (Pignatti, 1971)]. If 
this is followed, then subgenus Limonium would appear paraphyletic. The isolated taxonomic position of $L$. echioides was previously suggested by Baker (1953) and Bohkari (1973). They pointed out that section Schi zhymenium was heterogeneous and that the differences between $L$. echioides and the other two taxa included within the section ( $L$. owerinii and L. cabulicum) were so remarkable that L. echioides should be accommodated in a section of its own. Molecular analysis of the latter speciesis needed before a reassessment of the placement of L. echioides within section Limonium can be made.

\section{ACKN O WLEDG MENTS}

We express our gratitude to those colleagues who supported different parts of this research in their labs, especially A. Culham, J . Parker, and S. Kresovich, and those who assisted in different aspects of this work, such as V. Fernández-Pedrosa, A. Granell, and F. Bakker, among many others. We thank A. Latorre for her critical reading of the manuscript and three anonymous reviewers who helped to improve a previous version. This work has been funded by DGICYT Project PB93-1350 and DGES Project PB97-1369 and by Conselleria de Medi Ambient, Generalitat Valenciana. C.P. has been the recipient of a predoctoral fellowship from Conselleria de E ducació i Ciència, Generalitat Valenciana.

\section{REFERENCES}

Aimi, T., Yamada, T., and Murooka, Y. (1992). Nucleotide sequence and secondary structure of 5.8S rRNA from the unicellular green alga, Chlorella ellipsoidea. Nucleic Acids Res. 20: 6098-6098.

Albert, V. A., Williams, S. E., and Chase, M. W. (1992). Carnivorous plants: Phylogeny and structural evolution. Science 257: 14911494.

Baker, H. G. (1953). Dimorphism and monomorphism in the Plumbaginaceae. Ann. Bot (London) 17: 433-455.

Bakker, F. T., Olsen, J. L., and Stam, W. T. (1995). Evolution of nuclear rDNA ITS sequences in the Cladophora albida/ sericea clade (Clorophyta). J . Mol . Evol . 40: 640-651.

Baldwin, B. G., Sanderson, M. J ., Porter, J . M., Wojciechowski, M. F., Campbell, C. S., and Donoghue, M. J . (1995). The ITS region of nuclear ribosomal DNA: A valuable source of evidence on Angiosperm phylogeny. Ann. Missouri Bot. Gard. 82: 247-277.

Bloch, W. (1991). A biochemical perspective of the polymerase chain reaction. Biochemistry 30: 2735-2747.

Bobola, M. S., Smith, D. E., and Klein, A. S. (1992). Five major nuclear ribosomal repeats represent a large and variable fraction of the genomic DNA of Picea rubens and P. mariana. Mol. Biol. Evol. 9: 125-137.

Boissier, J. P. (1848). "The Candolle. A.P. Prodromus Systematics Naturalis Regni Vegetabilis," Vol . xii. Masson, Paris.

Bokhari, M. H. (1973). Variation and taxonomic importance of anatomical characters in Limonium. Notes R. Bot. Gard. Edinburgh 32: 275-290.

Bremer, B. (1991a). Restriction data from chloroplast DNA for phylogenetic reconstruction: Is there only one accurate way of scoring? Plant Syst. Evol. 175: 39-54.

Bremer, B., and J ansen, R. K. (1991b). Comparative restriction site mapping of chloroplast DNA implies new phylogenetic relationships within Rubiaceae. Am. J . Bot. 78: 198-213.

Brunsfeld, S. J ., Soltis, D. E., and Soltis, P. S. (1992). Evolutionary patterns and processes in Salix sect. Longifoliae: Evidence from chloroplast DNA. Syst. Bot. 17: 239-256.

Campbell, C. S., Donoghue, M. J ., Baldwin, B. G., Alice, L. A., and Wojciechowski, M. F. (1997). Persistent nuclear ribosomal DNA sequence polymorphism in the Amelanchier agamic complex (Rosaceae). Mol. Biol. Evol. 14: 81-90.

Chase, M. W., Soltis, D. E., Olmstead, R. G., Morgan, D., Les, D. H., Mishler, B. D., Duvall, M. R., Price, R. A., Hills, H. G., Qiu, Y. L., Kron, H. G., Rettig, J . H., Conti, E., Palmer, J . D., Manhart, J . R., Systma, K. J ., Michaels, H. J ., Kress, W. J., Karol, K. G., Clark, W. D., Hedrén, M., Gaut, B. S., J ansen, R. K., Kim, K.-J ., Wimpee, C. F., Smith, J. F., Furnier, G. R., Xiang, Q.-Y., Plunkett, G. M., Soltis, P. S., Swensen, S. M., Williams, S. E., Gadek, P. A., Quinn, C. J ., Eguiarte, L. E., Golenberg, E., Learn, G. H., J r., Graham, S. W., Barrett, S. C. H., Dayanandan, S., and Albert, V. A. (1993). Phylogenetics of seed plants: An analysis of nucleotide sequences from the plastid gene rbcL. Ann. Missouri Bot. Gard. 80: 528-580.

Clegg, M. T. (1987). Plant molecular evolution. Preface. Am. Nat. 130: s1-s5.

Crease, T. J ., and Lynch, M. (1991). Ribosomal DNA variation in Daphnia pulex. Mol. Biol. Evol. 5: 620-640.

Dixon, M. T., and Hillis, D. M. (1993). Ribosomal RNA secondary structure: Compensatory mutations and implications for phylogenetic analyses. Mol. Biol. Evol. 10: 256-267.

Dolcher, T., and Pignatti, S. (1971). Un'ipotesi sull'evoluzione dei Limonium del bacino del Mediterraneo. Giorn. Bot. Ital. 105: 95-107.

Donoghue, M. J ., and Cantino, C. R. (1988). Paraphyly, ancestors, and the goals of taxonomy: A botanical defense of cladism. Bot. Rev. 54: 107-128.

Doyle, J . (1991). DNA and higher plants systematics: Some examples from the legumes. In "Molecular Techniques in Taxonomy" (G. M. Hewitt et al., Eds.), pp. 101-115. Springer-Verlag, Berlin.

Doyle, J . J . (1992). Gene trees and species trees: Molecular systematics as one-character taxonomy. Syst. Bot. 17: 144-163.

Doyle, J . J ., and Doyle, J . L. (1993). Chloroplast DNA phylogeny of the Papilionoid Legume Tribe Phaseoleae. Syst. Bot. 18: 309-327.

Doyle, J. J ., Doyle, J . L., Brown, A. H., and Grace, J. P. (1990). Multiple origins of polyploids in the Glycine tabacina complex inferred from chloroplast DNA polymorphism. Proc. Natl. Acad. Sci. USA 87: 714-717.

Edelman, I., Olson, S., and Devereux, J . (1995). Wisconsin sequence analysis package.

Erben, M. (1978). Die gattung Limonium im Sudwestmediterranen raum. Mitt. Bot. München 114: 361-631.

Erben, M. (1979). Karyotype differentiation and its consequences in Mediterranean Limonium. Webbin 34: 409-417.

Erben, M. (1993). Limonium. In "Flora Iberica” (S. Castroviejo, C. J edo, S. Cirujano, M. Lainz, P. Montserrat, R. Morales, F. Muñoz, C. Navarro, J . Paiva, and C. Soriano, Eds.), pp. 2-143. Real J ardín Botánico Madrid-CSIC, Madrid.

Felsenstein, J . (1981). Evolutionary trees from DNA sequences: A maximum likelihood approach. J. Mol. Evol. 17: 368-376.

Felsenstein, J . (1985). Confidence limits on phylogenies: An approach using the bootstrap. Evolution 39: 783-791.

Felsenstein, J . (1992). Phylogenies from restriction sites: A maximumlikelihood approach. Evolution 46: 159-173.

Felsenstein, J . (1993). PHYLIP: Phylogenetic Inference Package, version 3.5c. Univ. of Washington, Seattle.

Fuertes, J ., Rosselló, J . A., and Nieto Feliner, G. (1999). Molecular evidence for the compilospecies model of reticulate evolution in Armeria (Plumbaginaceae). Syst. Biol., in press.

Greuter, W., Burdet, H. M., and Long, G. (1989). "Med-Checklist," Conservatoire et J ardin Botaniques de la Ville de Genève, Genève. 
Harris, S. A., and Ingram, R. (1991). Chloroplast DNA and biosystematics: The effects of intraspecific diversity and plastid transmission. Taxon 40: 393-412.

Hershkovitz, M. A., and Zimmer, E. A. (1996). Conservation patterns in angiosperm rDNA ITS-2 sequences. Nucleic Acids Res. 15: 2857-2867.

Hillis, D. M. (1991). Discriminating between phylogenetic signal and random noise in DNA sequences. In "Phylogenetic Analysis of DNA Sequences" (M. M. Miyamoto and J . Cracraft, Eds.), pp. 278-294. Oxford Univ. Press, Oxford.

Hillis, D. M., and Huelsenbeck, J. P. (1992). Signal, noise, and reliability in molecular phylogenetic analysis. J . Hered. 83: 189195.

Hillis, D. M., Moritz, C., Porter, C. A., and Baker, R. J. (1991). Evidence for biased gene conversion in concerted evolution of ribosomal DNA. Science 251: 308-310.

Holsinger, K. E., and J ansen, R. K. (1993). Phylogenetic analysis of restriction site data. Methods Enzymol . 224: 439-455.

Huelsenbeck, J. P., and Hillis, D. M. (1993). Success of phylogenetic methods in the four-taxon case. Syst. Biol. 42: 247-264.

J ukes, T. H., and Cantor, C. R. (1969). Evolution of protein molecules. In "Mammalian Protein Metabolism" (H. N. Munro, Ed.), pp. 21-132. Academic Press, New York.

Karvonen, P., and Savolainen, O. (1993). Variation and inheritance of ribosomal DNA in Pinus sylvestris L. (Scots pine). Heredity 71: 614-622.

Kim, K.-J ., and J ansen, R. K. (1994). Comparisons of phylogenetic hypotheses among different data sets in dwarf dandelions (Krigia): Additional information from internal transcribed spacer sequences of nuclear ribosomal DNA. Plant Syst. Evol. 190: 157- 185.

Ko, K., Strauss, N. A., and Williams, J . P. (1984). The localization and orientation of specific genes in the chloroplast chromosome of Vicia faba. Curr. Genet. 8: 359-367.

Kumar, S., Tamura, K., and Nei, M. (1993). MEGA. Molecular Evolutionary GeneticAnalysis version 1.0. The Pennsylvania State Univ.

Linczveski, I. (1968). Tentamentum systematis ordinis Plumbaginalium Lindl. Novit. Syst. Plant. Vascul. (Leningrad) 1968: 171177.

Liu, J . S., and Schardl, C. L. (1994). A conserved sequence in internal transcribed spacer-1 of plant nuclear RNA genes. Plant Mol. Biol. 26: 775-778.

Lledó, M. D., Crespo, M. B., Cameron, K. M., Fay, M. P., and Chase, M. W. (1998). Systematics of Plumbaginaceae based upon cladistic analysis of rbcL sequence data. Syst. Bot. 23: 21-29.

Maddison, D. R. (1991). The discovery and importance of multiple islands of most-parsimonious trees. Syst. Zool . 403: 315-328.

Maniatis, T., Fristsh, E. F., and Sambrook, J . (1982). "Molecular Cloning: A Laboratory Manual," Cold Spring Harbor Laboratory Press, Cold Spring Harbor, NY.

McDade, L. A. (1992). Hybrids and phylogenetic systematics. II. The impact of hybrids on cladistic analysis. Evolution 46: 1329-1346.

Mertens, L. (1993). Origins of genotypic variation in N orth American dandelions inferred from ribosomal DNA and chloroplast DNA restriction enzyme analysis. Evolution 47: 136-151.

Nei, M. (1987). “Molecular Evolutionary Genetics," Columbia Univ. Press, New York.

Nei, M. (1991). Relative efficiencies of different tree-making methods for molecular data. In "Phylogenetic Analysis of DNA Sequences" (M. M. Miyamoto and J . Cracraft, Eds.), pp. 90-128. Oxford Univ. Press, New York.

Nei, M., and Miller, J. C. (1990). A simple method for estimating average number of nucleotide substitutions within and between populations from restriction data. Genetics 125: 873-879.
Nicholas, K. B., and Nicholas, H. B., J r. (1997). GeneDoc: A tool for editing and annotating multiple sequence alignments. Software distributed by the author.

Olsen, G. J ., Matsuda, H., Hagstrom, R., and Overbeek, R. (1994). fastDNAml: A tool for construction of phylogenetic trees of DNA sequences using maximum likelihood. Comput. Appl. Biosci. 10: 41-48.

Olsthoorn, R. C. L., Licis, N., and van Duin, J . (1994). Leeway and constraints in the forced evolution of a regulatory RNA helix. EMBO J . 13: 2660-2668.

Palmer, J . D. (1991). Plastid chromosomes: Structure and evolution. In "The Molecular Biology of Plastids: Cell Culture and Somatic Cell Genetics of Plants" (L. Bogorad and I. K. Vasil, Eds.), pp. 5-53. Academic Press, New York.

Pau, C. (1898). Noticia de algunas plantas curiosas o nuevas. Actas Soc. Esp. Hist. Nat. 27: 196-200.

Pax, F. (1897). “Statice: Die Natürlichen Pflanzenfamilien," Engler \& Prantl, Leipzig.

Pignatti, S. (1971). Limonium. In "Flora Europea” (T. G. Tutin, J . S. Heywood, N. A. Burges, D. M. Moore, S. M. Valentine, S. M. Walters, and D. A. Webb, Eds.), pp. 81-125. CambridgeUniv. Press. Cambridge.

Richards, A. J . (1986). "Plant Breeding Systems," Allen \& Unwin, London.

Richards, A. J ., Kirschner, J ., Stepánek, J ., and Marhold, K. (1996). Apomixis and taxonomy: An introduction. Folia Geobot. Phytotax. 31: 281-282.

Rieseberg, L. H., and Brunsfeld, S. J . (1992). Molecular evidence and plant introgression. In "Molecular Systematics of Plants" (P. S. Soltis, D. E. Soltis, and J .J . Doyle, Eds.), pp. 151-176. Chapman \& Hall, New York.

Roel ofs, D., van Velzen, J., Kuperus, P., and Bachmann, K. (1997). Molecular evidence for an extinct parent of the tetraploid species Microseris acuminata and M. campestris (Asteraceae, Lactuceae). Mol. Ecol. 6: 641-649.

Saitou, N., and Nei, M. (1987). The neighbor-joining method: A new method for reconstructing phylogenetic trees. Mol. Biol. Evol. 4: 406-425.

Sang, T., Crawford, D. J ., and Stuessy, T. F. (1995). Documentation of reticulate evolution in peonies (Paeonia) using internal transcribed spacer sequences of nuclear ribosomal DNA: Implications for biogeography and concerted evolution. Proc. Natl. Acad. Sci. USA 92: 6813-6817.

Sankoff, K. (1975). Minimal mutation trees of sequences. SIAM J . Appl. Math. 28: 35-42.

Soltis, D. E., and Kuzoff, R. K. (1995). Discordance between nuclear and chloroplast phylogenies in the Heuchera group (Saxifragaceae). Evolution 49: 727-742.

Soltis, D. E., Soltis, P. S., and Milligan, B. G. (1992). Intraspecific chloroplast DNA variation: Systematic and phylogenetic implications. In "Molecular Systematics of Plants" (P. S. Soltis, D. E. Soltis, and J . J . Doyle, Eds.), pp. 117-150. Chapman \& Hall, New York.

Soltis, D. E., Soltis, P. S., Ranker, T. A., and Ness, B. D. (1989). Chloroplast DNA variation in a wild plant, Tolmiea menziesii. Genetics 121: 819-826.

Soltis, K. E., Soltis, P. S., and Thompson, J . N. (1992). Chloroplast DNA variation in Lithophragma (Saxifragaceae). Syst. Bot. 17: 607-619.

Sugiura, M., Shinozaki, K., Zaita, N., Kusuda, M., and Kumano, M. (1986). Clone bank of the tobacco (Nicotiana tabacum) chloroplast genome as a set of overlapping restriction endonuclease fragments: Mapping of eleven ribosomal protein genes. Plant Sci . 44: 211-216.

Suh, Y., Thien, L. B., Reeve, H. E., and Zimmer, E. Z. (1993). Molecular evolution and phylogenetic implications of internal 
transcribed spacer sequences of ribosomal DNA in Winteraceae. Am. J . Bot. 80: 1042-1055.

Swofford, D. L. (1993). PAUP: Phylogenetic Analysis Using Parsimony, version 3.1. Laboratory of Molecular Systematics, Smithsonian Inst.

Swofford, D. L., Olsen, G. J ., Waddell, P. J ., and Hillis, D. M. (1996). Phylogenetic inference. In "Molecular Systematics" (D. M. Hillis, C. Moritz and B. K. Mable, Eds.), 2nd ed., pp. 407-514. Sinauer, Sunderland, MA.

Van der Sande, C. A. F. M., Kwa, M., van Nues, R. W., van Heerikhuizen, H., Raué, H. A., and Planta, R. J . (1992). Functional analysis of internal transcribed spacer 2 of Saccharomyces cerevisiaeribosomal DNA. J . Mol. Biol. 223: 899-910.

van Houten, W. H. J ., Scarlett, N., and Bachmann, K. (1993). Nuclear DNA markers of theAustralian tetraploid Microseris scapigera and its North American diploid relatives. Theor. Appl. Genet. 87: 498-505.

Van Nues, R. W., Rientjes, J . M. J ., van der Sande, C. A. F. M., Zerp, S. F., Sluiter, C., Venema, J ., Planta, R. J ., and Raué, H. A. (1994).
Separate structural elements within internal transcribed spacer 1 of Sacharomyces cerevisiae precursor ribosomal RNA direct the formation of 17S and 26S rRNA. Nucleic Acids Res. 22: 912-919.

Wendel, J . F., Schnabel, A., and Seelanan, T. (1995). Bidirectional interlocus concerted evolution following allopolyploid speciation in cotton (Gossypium). Proc. Natl. Acad. Sci. USA 92: 280-284.

White, T. J ., Bruns, T., Lee, S., and Taylor, J . (1990). Amplification and direct sequencing of fungal ribosomal RNA genes for phylogenetics. In "PCR Protocols: A Guide to Methods and Applications" (M. A. Innis, D. H. Golfand, J .J . Sninsky, and T. J . White, Eds.), pp. 315-322. Academic Press, New York.

Williams, E. S., Albert, V. A., and Chase, M. W. (1994). Relationships of Droseraceae: A cladistic analysis of $\mathrm{rbcL}$ sequence and morphological data. Am. J . Bot. 81: 1027-1037.

Yeh, L. C. C., and Lee, J . C. (1991). Higher order structure of the 5.85 rRNA sequence within the yeast $35 \mathrm{~S}$ precursor ribosomal RNA synthesized in vitro. J . Mol. Biol. 217: 649-659.

Zuker, M. (1989). On finding all suboptimal foldings of an RNA molecule. Science 244: 48-52. 